\title{
Do current levels of air pollution kill? The impact of air pollution on population mortality in England
}

\author{
Katharina Janke ${ }^{\mathrm{a}}$, Carol Propper ${ }^{\mathrm{b}}$, and John Henderson ${ }^{\mathrm{c}}$ \\ ${ }^{\mathrm{a}} \mathrm{CMPO}$, University of Bristol, UK \\ ${ }^{b}$ University of Bristol, UK; Imperial College, London, UK; CEPR, London, UK \\ 'Department of Social Medicine, University of Bristol, UK
}

December 5, 2014

\begin{abstract}
The current air quality limit values for airborne pollutants in the UK are low by historical standards and are at levels that are believed not to harm health. We assess whether this view is correct. We examine the relationship between common sources of airborne pollution and population mortality for England. We use data at local authority level for 1998-2005 to examine whether current levels of airborne pollution, as measured by annual mean concentrations of carbon monoxide, nitrogen dioxide, particulate matter less than $1010 \mu \mathrm{m}$ in diameter $\left(\mathrm{PM}_{10}\right)$ and ozone, are associated with excess deaths. We examine all-cause mortality and deaths from specific cardiovascular and respiratory causes that are known to be exacerbated by air pollution. The panel nature of our data allows us to control for any unobserved time-invariant associations at local authority level between high levels of air pollution and poor population health and for common time trends. We estimate multi-pollutant models to allow for the fact that three of the pollutants are closely correlated. We find that higher levels of $\mathrm{PM}_{10}$ and ozone are associated with higher mortality rates, and the effect sizes are considerably larger than previously estimated from the primarily time series studies for England
\end{abstract}

KEY WORDS: air pollution, child health, asthma, avoidance behaviour, panel analysis JEL I12, I18, Q53, Q58 


\section{Introduction}

The current levels of airborne pollutants in many OECD countries are low by historical standards. The limits on air pollution set by the regulatory authorities are also low by these standards. Yet recent research from the USA has shown that there are adverse effects from airborne pollution for infants even at these levels (Currie and Neidell 2005). This paper focuses on the impact of airborne pollutants on population health in England. England is of interest because it has average pollutant levels that are low (around 30\% lower than those examined in recent studies from the United States (Currie and Neidell 2005, Neidell 2004)) and the limit values allowed by the regulatory authorities are set reflecting a belief that there is a safe threshold at which no significant health effects can be observed. ${ }^{1}$ The aim of the paper is to test this belief by examining whether the current levels of airborne pollutants in England are associated with adverse health effects - as measured by mortality - for the population.

Adults have been the main focus of most of the research on air pollution and excess mortality. Previous studies of the impact of airborne pollutants on mortality rates are basically of two kinds. The first exploit high frequency time series data on levels of air pollution and number of deaths to examine the time series relationship. Such studies measure the acute effects of air pollution and generally focus on a single pollutant. However, the focus on a single pollutant may over-estimate its impact, as several of the common airborne pollutants are correlated, because they are components of traffic emissions. In addition, if temporarily elevated levels of pollution hasten the deaths of frail persons who would have died within days or weeks, then the effects of pollution are over-estimated. The second type of study examines the impact of living in cities with different levels of pollution. Whilst these studies capture more than the short term effects of pollution, comparisons of cities suffer from potential omitted variable bias, as it is likely that these cities are different in important ways other than in their level of pollution. So observed cross-sectional differences in deaths may not be causal (Chay and Greenstone 2003).

In this paper, we use the following design to deal with these problems. We take as the unit of observation the primary unit of local government in the UK (the local authority) and examine the relationship between annual mortality rates and annual mean concentrations of four common air pollutants over time at this level. The use of a panel allows us to fully control for time-varying determinants of death that are national in scope and factors that differ across local areas that remain fixed over time, so we can isolate the impact of pollution from other unobserved differences between local authorities. The use of a time period of a year means this design will not detect the small changes in life expectancy (changes of a few days) that may underlie the associations found in time series studies. Focussing on annual mortality rates also reduces one aspect of model uncertainty found in time series studies (see Clyde

\footnotetext{
${ }^{1}$ Seehttp://uk-air.defra.gov.uk/.
} 
(2000) and Koop and Tole (2004)). Additionally, annual mortality rates for local authorities are readily available, whereas daily, weekly or monthly rates are not publicly available for confidentiality reasons. Finally, the research design allows us to control for the correlation between the levels of common airborne pollutants.

Despite its advantages this design has been little used to examine pollution and mortality. In one of the few studies using this approach, Chay et al. (2003) examine the effect of particulate matter on adult mortality in the US during the 1970s. They find no impact of this pollutant on adult mortality. However, the pollutant measure used during the period covered by their study (total suspended particles) was possibly too imprecise to pick up mortality effects.

Our panel begins in 1998 after Local Air Quality Management came into effect in the UK in December 1997. It ends in 2005. Local Air Quality Management required local authorities to assess the air quality in their areas and, as a result, local authorities installed additional air pollution monitoring stations that supplement the existing national monitoring network. ${ }^{2}$ This provides a dense network of air pollution monitors that allows us, using spatial matching methods, to assign air pollution measures for about $90 \%$ of local authorities and all of the local authorities with large populations. Our analysis focuses on the pollutants carbon monoxide $(\mathrm{CO})$, nitrogen dioxide $\left(\mathrm{NO}_{2}\right)$, particulate matter less than $10 \mu \mathrm{m}$ in diameter $\left(\mathrm{PM}_{10}\right)$, and ozone $\left(\mathrm{O}_{3}\right){ }^{3}$ UK (and European) legislation sets limit values for these pollutants, because they have deleterious effects on human health. ${ }^{4}$

We examine deaths from all causes and then focus on deaths from specific causes - diseases of the cardiovascular and respiratory system - which have been shown by recent medical literature to be associated with air pollution (Pope and Dockery 2006). We control for observed factors that may be correlated with pollution but are independent causes of early deaths, such as education, employment and lifestyle. We estimate multiple pollutant models to isolate the impact of specific pollutants. We also subject our results to a large number of specification tests, including 'placebo' tests for a spurious association between air pollution at local authority level and death rates by examining the association of air pollution with two causes of death which are unlikely to be driven by air pollution. Our findings suggest that the relatively low levels of pollution currently permitted in the UK are associated with mortality rates in the population. We find significant effects of both $\mathrm{PM}_{10}$ and $\mathrm{O}_{3}$ on mortality. The magnitudes of these effects are both statistically and economically significant.

\footnotetext{
${ }^{2}$ Note that the local authorities are not the same bodies that are responsible for providing health care or meeting health targets.

${ }^{3}$ Earlier studies have examined sulphur dioxide pollution. We focus here on those pollutants whose levels are widely measured, reflecting current concerns over their impacts on health.

${ }^{4}$ See Appendix Appendix A for sources and effects of of these pollutants and Appendix Appendix B for the air quality standards in operation in England during our sample period.
} 


\section{An overview of the literature on air pollution and mortality}

The literature on air pollution and mortality is dominated by two types of study: time series studies of the association between short-term variations in air pollution and mortality and cross-sectional studies of cohorts followed over time or of cities with long-term differences in pollution. Time series studies regress daily counts of deaths for a geographical area onto daily means of air pollutant concentrations, controlling for confounding factors such as temperature, humidity and barometric pressure. Exploiting short-term variation to identify pollutant effects eliminates the effects of lifestyle factors such as exercise and diet, because these factors do not change on the short run. Systematic reviews of the numerous published time series studies report significant associations between air pollutants and mortality, with mean estimates suggesting that per $10 \mu \mathrm{g} / \mathrm{m}^{3}$ increase in $\mathrm{NO}_{2}, \mathrm{PM}_{10}$ or $\mathrm{O}_{3}$ or per $1 \mathrm{mg} / \mathrm{m}^{3}$ increase in CO mortality increases by less than $1 \%$ (see, inter alia, Stieb et al. (2002), Bell et al. (2005) and Department of Health (2006)).

There are two problems interpreting the findings from time series studies. The daily time series design can only identify the acute effect of pollution. Part of the increase in mortality may be caused by deaths of individuals who would have died only a few days later from other causes (an issue known as "harvesting"). So, such studies may over-estimate the impact of air pollution on health. In addition, levels of different pollutants may be strongly correlated; identifying which pollutant is causing the increased deaths is therefore difficult from studies based on short-term fluctuations in one pollutant.

Ecological studies of associations between spatial variations in air pollution and spatial variations in mortality compare mortality in highly polluted areas with mortality in less polluted areas, using population average values to control for other risk factors such as smoking, deprivation and education. Typically, they suggest that a pollutant increase of $10 \mu \mathrm{g} / \mathrm{m}^{3}$ increases mortality by about 3\% (Wilson and Spengler 1996). But these studies face severe omitted variables problems, as they typically do not control for many individual or community level variables which may be correlated with pollution. ${ }^{5}$

Finally, cohort studies use pollutant concentrations averaged over a year or longer periods. Few such studies exist and there are none for the UK. Two key U.S. studies estimate an increase in mortality risk of between $4 \%$ and $14 \%$ per $10 \mu \mathrm{g} / \mathrm{m}^{3}$ increase in $\mathrm{PM}_{2.5}$ (Pope et al. 2002, Dockery et al. 1993). Estimated effects on cardiopulmonary mortality are generally larger. Estimates of the effects of $\mathrm{CO}, \mathrm{NO}_{2}$ and $\mathrm{O}_{3}$ tend to be insignificant (Krewski et al. 2000). The only long-term studies for Europe are one for Norway, which finds a mortality risk increase of $8 \%$ per $10 \mu \mathrm{g} / \mathrm{m}^{3}$ increase in nitrogen oxides $\left(\mathrm{NO}_{2}+\mathrm{NO}\right)$ for men (Nafstad et al. 2004) and one for the Netherlands, which finds positive but insignificant effect estimates for $\mathrm{NO}_{2}$

\footnotetext{
${ }^{5} \mathrm{~A}$ very small number of studies uses exogenous changes in air pollution. Clancy et al. (2002) used the ban on coal sales in Dublin in 1990, which reduced average black smoke concentrations. Studies of extreme pollution episodes use one large fluctuation in air pollutant concentrations to identify short-term effects. A classic example is the Great Smog of London in 1954 that caused 4,000 excess deaths (Wilkins 1954).
} 
(Hoek et al. 2002). Because of their design, cohort studies are expensive and take long time to complete. In addition, cohort studies may suffer from omitted variable bias, as the cities or zip codes which are compared may differ from each other in important ways other than just their levels of air pollution.

Within the economics literature, there have been several studies for the US which show that current levels of pollution are associated with poor health outcomes. Currie and Neidell (2005) examine the impact of $\mathrm{CO}, \mathrm{PM}_{10}$ and $\mathrm{O}_{3}$ on infant deaths in California over the 1990s. Using individual-level weekly data, they find a significant effect of $\mathrm{CO}$ on infant mortality. Aggregating up their data to zip code-quarter level, however, they find no effect for CO, but a significant effect for $\mathrm{PM}_{10}$. The pollution levels in California during the 1990s are higher than the pollutant concentrations in England during the period we examine: the sample mean of $\mathrm{PM}_{10}$ in Currie and Neidell (2005) is $39.4 \mu \mathrm{g} / \mathrm{m}^{3}$, whereas our sample mean is $24.7 \mu \mathrm{g} / \mathrm{m}^{3}$. Chay and Greenstone (2003) exploit variation across US counties in the depth of a sudden economic recession in 1980 to 1982 to identify the effect of a medium-term reduction in total suspended particles (TSP - particles with diameter $\leq 40 \mu \mathrm{m}$ ) on infant mortality. Again, pollution levels are higher than currently in England. ${ }^{6}$ They find a significant effect of TSP reductions on decreases in infant mortality rates.

In one section of their paper, Chay et al. (2003) use the same approach as we adopt here, using US counties as the unit of observation. They exploit within-county time-series variation in TSP levels to study the effect of air pollution on mortality in adults over 50 years and adults aged 65 to 84 years in 1969 to 1974. The average pollution level in their data is twice the level we examine. ${ }^{7}$ However, they find no association between their measure of air pollution and mortality, perhaps because TSP are a rather crude measure of air pollution.

\section{Our empirical approach}

Our unit of analysis is a local authority, which is the main unit of political administration below the national level in the UK. There are 354 local authorities in England, with an average population of around 140,000 people, ranging from just over 2,000 to just over 1 million. ${ }^{8}$ Local authorities are aggregated into 9 Government Office regions. Figure 1 shows the location and size of local authorities and the Government Office regions.

\footnotetext{
${ }^{6} \mathrm{TSP}$ is not measured in England during our sample period. To compare pollution levels, we convert TSP levels using 0.55 as $\mathrm{PM}_{10}$ /TSP ratio. In a review of studies of the acute effects of particles, Dockery and Pope (1994) use this ratio, based on guidelines from the US Environmental Protection Agency. Chay and Greenstone (2003) report TSP levels between 56.4 and $71.1 \mu \mathrm{g} / \mathrm{m}^{3}$, which is equivalent to $\mathrm{PM}_{10}$ levels between 31 and $39 \mu \mathrm{g} / \mathrm{m}^{3}$, one and a half times our sample mean of $24.7 \mu \mathrm{g} / \mathrm{m}^{3}$.

${ }^{7}$ Using 0.55 as $\mathrm{PM}_{10} / \mathrm{TSP}$ ratio their TSP sample mean of $93 \mu \mathrm{g} / \mathrm{m}^{3}$ is equivalent to a $\mathrm{PM}_{10}$ level of 51 $\mu \mathrm{g} / \mathrm{m}^{3}$. Our $\mathrm{PM}_{10}$ sample mean is $24.7 \mu \mathrm{g} / \mathrm{m}^{3}$.

${ }^{8}$ The smallest local authority used in the analysis here contains 34,000 people (Rutland) and the largest one million people (Birmingham).
} 


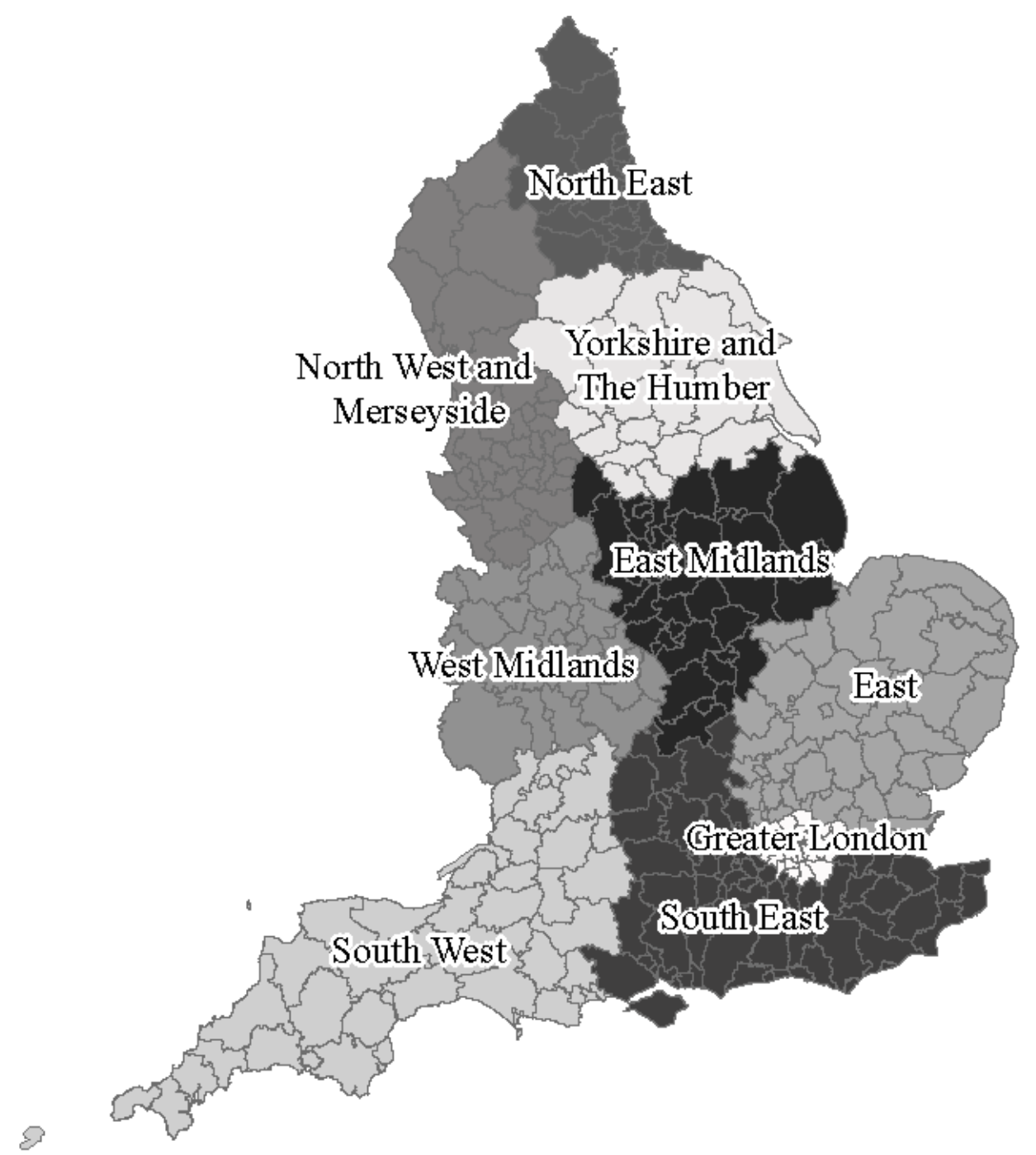

Figure 1: English local authorities and Government Office regions

We estimate equations of the following form:

$$
m_{i t}^{j}=\alpha+\boldsymbol{P}_{i t}^{\prime} \boldsymbol{\gamma}_{j}+\boldsymbol{Z}_{i t}^{\prime} \boldsymbol{\beta}_{j}+T^{j}+T_{r}^{j}+\mu_{i}^{j}+\varepsilon_{i t}^{j}
$$

where $i$ indexes the local authority, $t$ indexes the year, $r$ the region and $j$ the cause of death. $m_{i t}^{j}$ is the logarithm of one of six mortality rates (all-cause; all circulatory diseases; coronary heart disease; acute myocardial infarction; stroke; bronchitis, emphysema and other chronic obstructive pulmonary diseases $), \boldsymbol{P}_{i t}$ is a vector of air pollutants $\left(\mathrm{CO}, \mathrm{NO}_{2}, \mathrm{PM}_{10}, \mathrm{O}_{3}\right), \boldsymbol{Z}_{i t}$ is a vector of time-varying controls at local authority (or regional) level. $T^{j}$ is a time trend, $T_{r}^{j}$ is a region-specific time trend (regions are Government Office regions), $\mu_{i}^{j}$ is a local authority fixed effect, and $\varepsilon_{i t}$ is the error term for cause of death $j$. The coefficients of interest are the $\gamma^{j}$.

We first estimate the impact of each pollutant separately, but our main specifications 
include all pollutants together to allow for correlation between them. Identification comes from the time series variation in pollutant concentrations at local authority level. As our panel is short, within-group estimates may be biased, so we also estimate OLS models (in which the local authority fixed effect is replaced by a set of regional dummies) and three-year long-difference models (Griliches and Hausman 1986). In all our analyses we estimate robust standard errors and weight by the size of the local authority population.

\section{Data}

Data on air pollution comes from the UK Air Quality Archive, ${ }^{9}$ supplemented with data from four regional air quality networks managed by the same operator and from another four regional networks managed by the Environmental Research Group at King's College London. These sources provide data on a total of 192 automatic monitoring stations, of which 90, 174, 111 and 105 record concentrations of $\mathrm{CO}, \mathrm{NO}_{2}, \mathrm{PM}_{10}$ and $\mathrm{O}_{3}$, respectively. Figure 2 shows the positions of these monitors. ${ }^{10}$ The figure also shows the population densities of local authorities; the darker the shading, the more densely populated the area. It is clear from the figure that monitors are located in more densely populated areas, so that, while there is not equal coverage across areas, those areas with few monitoring stations are also areas of small populations.

We convert measurements given in volume ratios into mass units and compute daily pollutant concentrations if only hourly readings are available (see also Appendix $\mathrm{C}-1$ ). We use the daily mean of $\mathrm{NO}_{2}$ and $\mathrm{PM}_{10}$ and the daily maximum 8-h running mean of $\mathrm{CO}$ and $\mathrm{O}_{3}$ (the choice of unit is determined by the relevant pollution standard) to calculate annual means. We assign these annual pollutant concentrations to local authorities using a procedure similar to Currie and Neidell (2005). Using the geographical coordinates of the headquarters of a local authority, we calculate the distance between the headquarters and all monitoring stations. Then we use all monitoring stations whose distance to the headquarters is less than 30 miles (less than 10 miles for the London boroughs where there are many monitoring stations within relatively small distances) to calculate a weighted mean of the annual pollutant concentrations measured by these stations. The weight assigned to a monitor is the inverse of the distance between the headquarters and the monitor. Our measure is thus the distance-weighted mean of the annual mean pollutant concentrations at monitors in a 30 (10) mile radius of the headquarters of a local authority. We assign a measure of $\mathrm{CO}, \mathrm{NO}_{2}, \mathrm{PM}_{10}$ and $\mathrm{O}_{3}$ for at least two years to 312 out of 354 local authorities. The local authorities with missing air pollution measures are less populated areas.

To assess the accuracy of our pollution measure, we use our method to predict pollutant

\footnotetext{
${ }^{9}$ Prepared by AEA Energy \& Environment on behalf of the Department for Environment, Food \& Rural Affairs, www.http://uk-air.defra.gov.uk/.

${ }^{10}$ The map does not show two monitoring stations in Wales close to the English border, which we use for computing air pollution measures for local authorities in the West Midlands and in the North West.
} 
Population density, 2002

People per sq. km

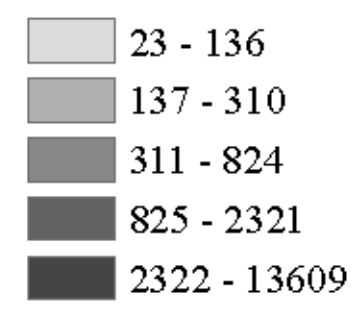

- Monitoring stations

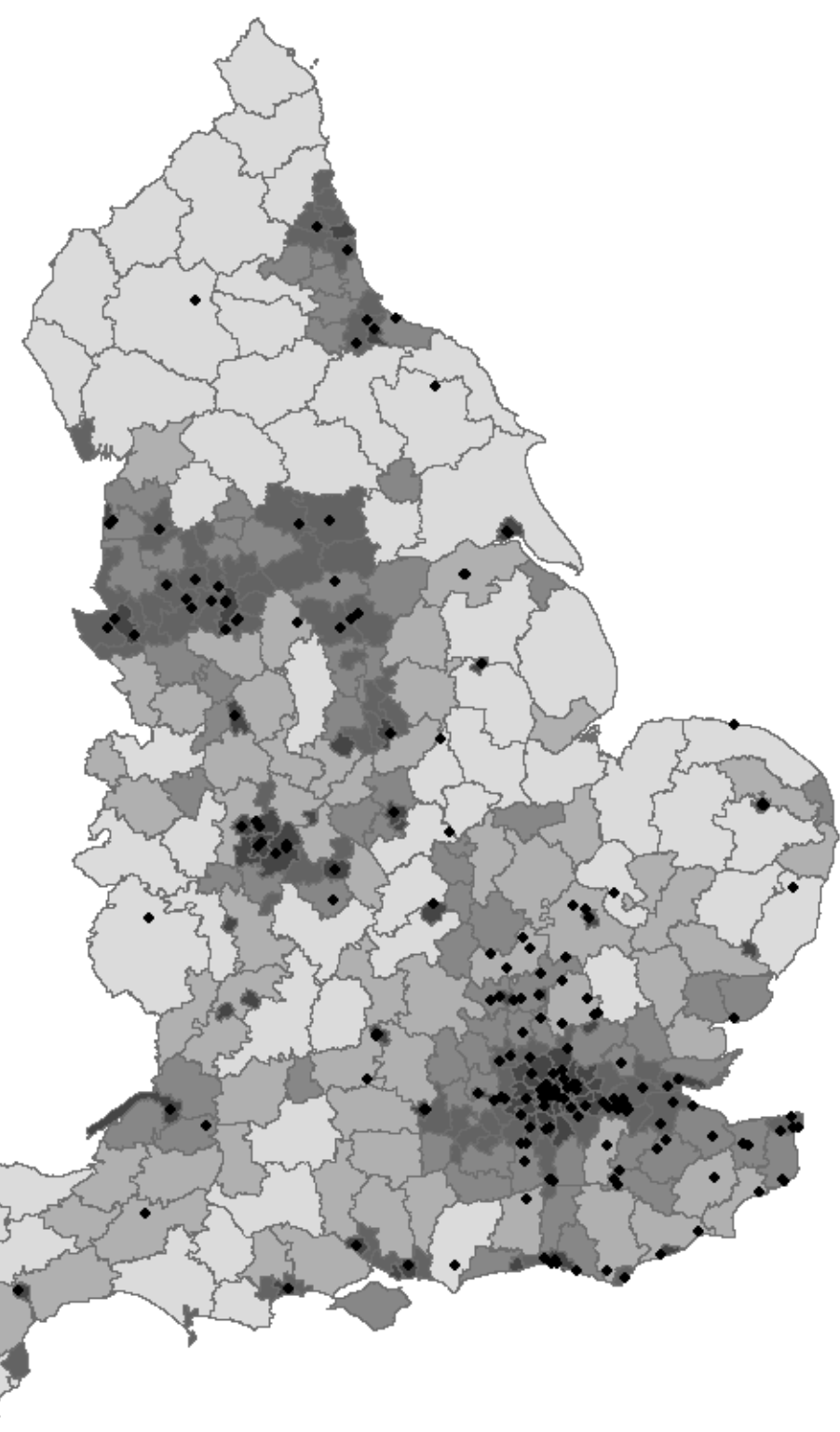

Data Source: Office for National Statistics

Figure 2: Positions of monitoring stations in England

concentrations at monitor locations and compare the predicted with the actual pollutant concentrations. For the underlying daily data the correlations are relatively high $(0.59,0.61$, 0.75 and 0.84 for $\mathrm{CO}, \mathrm{NO}_{2}, \mathrm{PM}_{10}$ and $\mathrm{O}_{3}$, respectively), indicating this approach will predict pollution at a location relatively well. The correlation coefficients for the annual data across all observations are lower at $0.44,0.45,0.40$ and 0.50 for $\mathrm{CO}, \mathrm{NO}_{2}, \mathrm{PM}_{10}$ and $\mathrm{O}_{3}$, respectively, due to the averaging induced by moving from daily to annual measures. However, the time series correlation between the predicted and actual annual values within monitoring stations 
is higher - 0.72, 0.47, 0.53 and 0.73 - for $\mathrm{CO}, \mathrm{NO}_{2}, \mathrm{PM}_{10}$ and $\mathrm{O}_{3}$ respectively. ${ }^{11}$ Since our identification strategy relies on time series variation within local authorities, the accuracy of our pollution measure seems reasonable.

Using measurements taken by stationary monitors at outside locations to calculate exposure to air pollution, there may be an issue of the extent to which measures of ambient air pollution predict personal exposure, as most people spend over $80 \%$ of their time indoors. Indoor air quality is often worse than outdoor air quality, because of cigarette smoke, paints, vinyl flooring, gas stoves, dust mites etc. However, empirical studies have shown that ambient levels of air pollutants and personal exposure to air pollutants are significantly correlated. ${ }^{12}$ Personal exposure is determined by outdoor concentrations, indoor concentrations and activity patterns. But as factors determining indoor concentrations, e.g. gas stoves and tobacco smoke, are not measured in our data we are not able to control for these. So we make the assumption that the major part of the variation in personal exposure to air pollutants is determined by changes in ambient levels of pollutants. We do, however, control for smoking rates and allow for separate regional time trends, which will pick up, inter alia, regional differences in changes in indoor pollution. ${ }^{13}$

Figure 3 presents quantile plots of our pollution measures, showing the time series variation in the annual pollutant levels. CO clearly declines over the years of our sample. There is also a reduction in the variation: the distance between the top two quantiles and the other three quantiles of the distribution falls over time. Measured at an annual level, no local authority exceeds the limit value, which is defined in terms of the daily maximum 8-h running mean. The annual mean level of $\mathrm{NO}_{2}$ initially declines before it peaks in 2003. The variation across local authorities remains pretty constant across the sample period. $\mathrm{NO}_{2}$ exceeds the limit value of $40 \mu \mathrm{g} / \mathrm{m}^{3}$ in many local authorities. Even in the year in which there were fewest instances of exceedances (2002), average annual levels of $\mathrm{NO}_{2}$ were higher than the limit value in $17 \%$ of local authorities. Annual means of $\mathrm{PM}_{10}$ fall until 2000, remaining relatively constant since then, apart from a peak in 2003. The distribution is pretty constant over the period. $\mathrm{PM}_{10}$ does not exceed $40 \mu \mathrm{g} / \mathrm{m}^{3}$, which is the limit value in force towards the end of our sample period, but it does exceed $20 \mu \mathrm{g} / \mathrm{m}^{3}$, the limit value which will come into effect at

\footnotetext{
${ }^{11}$ Figures are mean within station correlations. The median within station correlations are higher: 0.87 , $0.56,0.64$ and 0.79 .

${ }^{12}$ Georgoulis et al. (2002) use measurements of personal exposure to CO for 401 individuals in five European cities during a 48 hour period and find that ambient levels of CO are a significant determinant of personal exposure to CO. Kousa et al. (2001) use the same data and find that ambient levels of $\mathrm{NO}_{2}$ explain 11 to $19 \%$ of personal $\mathrm{NO}_{2}$ exposure variation. However, cross-sectional correlation coefficients between personal exposure and ambient pollutant concentrations can be misleading. For example, Janssen et al. (2000) study the timeseries correlation between ambient levels of $\mathrm{PM}_{2.5}$ and personal exposure to $\mathrm{PM}_{2.5}$ for elderly subjects with cardiovascular disease in two European cities. They find that personal exposure and ambient concentrations are highly correlated within subjects over time.

${ }^{13} \mathrm{O}_{3}$ has considerably lower indoor concentrations (Committee on the Medical Effects of Air Pollution 1997). Thus, for people who spend little time outdoors, personal exposure to $\mathrm{O}_{3}$ and ambient levels of $\mathrm{O}_{3}$ are not correlated. $\mathrm{O}_{3}$ concentrations, however, are elevated in summer, and people tend to spend more time outdoors in summer. Hence, our measure of $\mathrm{O}_{3}$ should explain at least part of the variation in personal exposure to $\mathrm{O}_{3}$.
} 

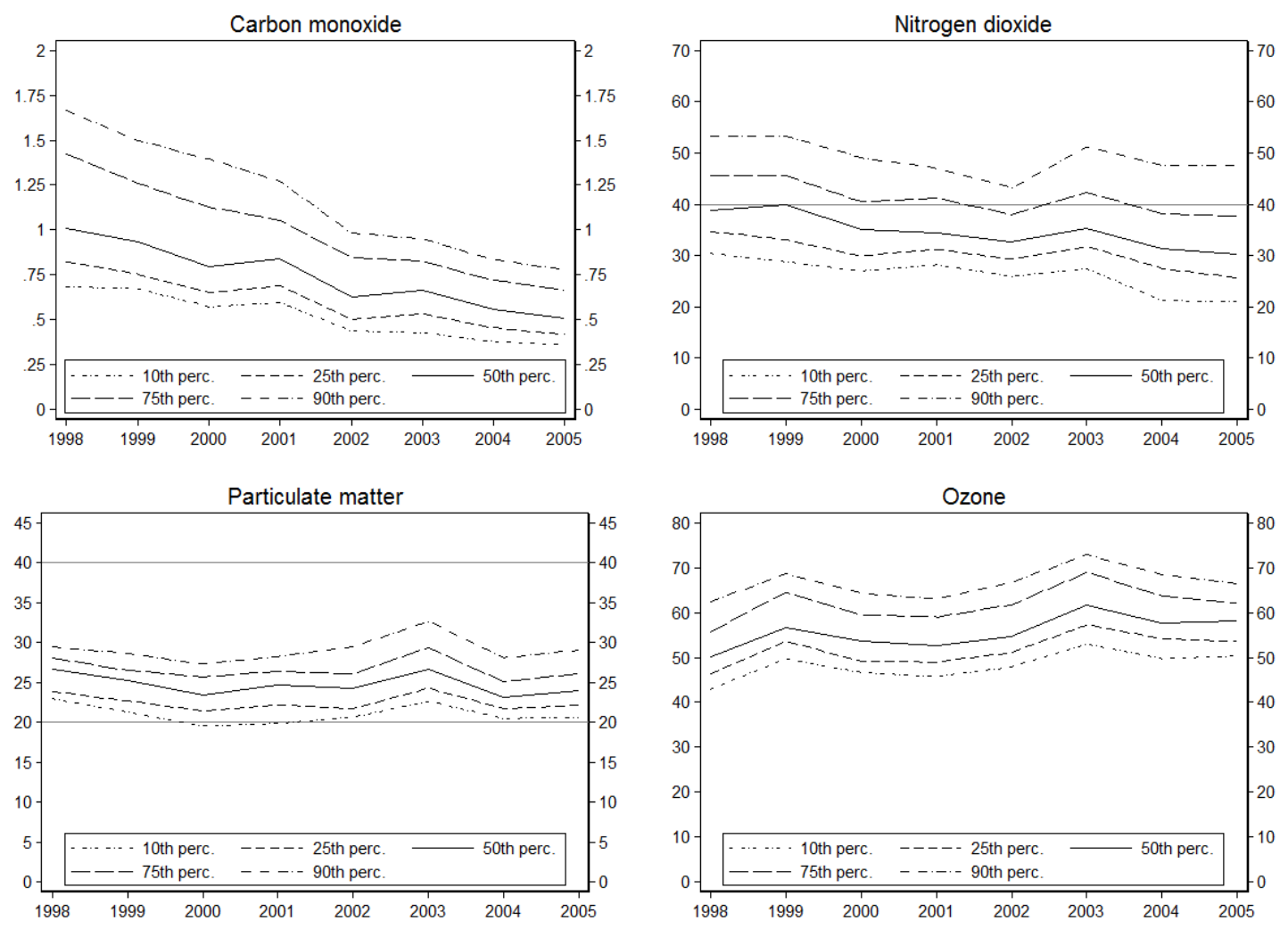

Figure 3: Quantile plots of annual pollutant concentrations in English local authorities.

Grey lines indicate annual limit values: the annual mean of $\mathrm{NO}_{2}$ must not exceed $40 \mu \mathrm{g} / \mathrm{m}^{3}$ by 31 December 2005, the annual mean of $\mathrm{PM}_{10}$ must not exceed $40 \mu \mathrm{g} / \mathrm{m}^{3}$ by 31 Decmeber 2004 and $20 \mu \mathrm{g} / \mathrm{m}^{3}$ by 31 December 2010 
the end of 2010. In contrast to the three other pollutants, annual means of $\mathrm{O}_{3}$ rise over the sample period. The variance of the distribution is fairly constant. There are two clear peaks in the series which affect all local authorities, one in 1999 and another one in 2003. Both years had above average sunshine, illustrating the potential difficulty of isolating the impact of $\mathrm{O}_{3}$ from that of weather conditions.

Table 1: Descriptive statistics for estimation sample $(n=2,338$, groups $=312)$

\begin{tabular}{|c|c|c|c|c|c|c|}
\hline Variable & Mean & SD & $\begin{array}{c}\text { Between } \\
\text { local author- } \\
\text { ities SD }\end{array}$ & $\begin{array}{c}\text { Within } \\
\text { local author- } \\
\text { ities SD }\end{array}$ & $\begin{array}{c}\text { Mean } \\
\text { in } 1998\end{array}$ & $\begin{array}{l}\text { Mean } \\
\text { in } 2005\end{array}$ \\
\hline \multicolumn{7}{|l|}{ Pollutants } \\
\hline $\mathrm{CO}\left(\mathrm{mg} / \mathrm{m}^{3}\right)$ & 0.80 & 0.34 & 0.26 & 0.23 & 1.13 & 0.55 \\
\hline $\mathrm{NO}_{2}\left(\mu \mathrm{g} / \mathrm{m}_{3}\right)$ & 36.6 & 9.1 & 8.5 & 3.8 & 41.0 & 33.2 \\
\hline $\mathrm{PM}_{10}\left(\mu \mathrm{g} / \mathrm{m}^{3}\right)$ & 24.7 & 3.3 & 2.9 & 1.7 & 26.3 & 24.2 \\
\hline $\mathrm{O}_{3}\left(\mu \mathrm{g} / \mathrm{m}^{3}\right)$ & 55.9 & 7.5 & 6.6 & 4.1 & 49.9 & 57.5 \\
\hline \multicolumn{7}{|l|}{ Mortality rates (per 100,000) } \\
\hline Mortality from all causes & 660.1 & 86.2 & 78.2 & 39.9 & 712.7 & 605.0 \\
\hline $\begin{array}{l}\text { Mortality from all circulatory } \\
\text { diseases }\end{array}$ & 243.7 & 42.0 & 31.6 & 28.4 & 286.3 & 202.2 \\
\hline $\begin{array}{l}\text { Mortality from coronary heart } \\
\text { diseases }\end{array}$ & 124.9 & 28.6 & 22.1 & 18.5 & 153.0 & 99.7 \\
\hline $\begin{array}{l}\text { Mortality from acute myocar- } \\
\text { dial infarction }\end{array}$ & 54.8 & 17.1 & 13.1 & 11.3 & 71.3 & 41.1 \\
\hline Mortality from stroke & 63.7 & 11.9 & 8.2 & 8.7 & 73.2 & 53.0 \\
\hline $\begin{array}{l}\text { Mortality from bronchitis, em- } \\
\text { physema and other COPD }\end{array}$ & 29.2 & 9.8 & 8.8 & 4.6 & 31.5 & 27.3 \\
\hline \multicolumn{7}{|l|}{ Control variables } \\
\hline Smoking rate (\%) & 25.7 & 2.4 & 1.7 & 1.7 & 27.4 & 23.6 \\
\hline Employment rate (\%) & 76.0 & 6.3 & 5.8 & 2.4 & 75.6 & 76.2 \\
\hline NVQ $4+$ level rate $(\%)$ & 24.4 & 7.9 & 7.6 & 3.2 & 22.2 & 26.6 \\
\hline $\begin{array}{l}\text { Annual mean of summer daily } \\
\text { maximum temperature }\left({ }^{\circ} \mathrm{C}\right)\end{array}$ & 18.6 & 1.2 & 1.0 & 0.6 & 17.8 & 18.7 \\
\hline $\begin{array}{l}\text { Annual mean of precipitation } \\
(\mathrm{mm})\end{array}$ & 2.2 & 0.63 & 0.51 & 0.38 & 2.4 & 1.7 \\
\hline \multicolumn{7}{|c|}{ Other mortality rates for robustness tests (per 100,000) } \\
\hline $\begin{array}{l}\text { Mortality from chronic liver } \\
\text { disease including cirrhosis }\end{array}$ & 8.9 & 4.4 & 3.5 & 2.7 & 7.8 & 9.6 \\
\hline $\begin{array}{l}\text { Mortality from infectious and } \\
\text { parasitic diseases }\end{array}$ & 5.7 & 2.9 & 2.0 & 2.1 & 5.0 & 7.2 \\
\hline
\end{tabular}

The top panel of Table 1 presents descriptive statistics for the pollution data. In addition to the average fall in all pollutants other than $\mathrm{O}_{3}$, it shows that the values of the withinlocal authority standard deviations range from $45 \%$ to $80 \%$ of the values of the between-local 
authorities standard deviations. This provides support for identification of air pollution effects by exploiting within-local authority variations. $\mathrm{CO}, \mathrm{NO}_{2}$ and $\mathrm{PM}_{10}$ are positively correlated, with correlation coefficients between 0.4 and 0.6. They are negatively correlated with $\mathrm{O}_{3}$, which tends to be higher in rural areas, with correlation coefficients between -0.2 and -0.5 (see Table C-2).

The second panel of Table 1 presents the mortality rates. Sources are given in Appendix C-1. We examine deaths from all causes as well as deaths from specific causes for which the medical literature suggests biologically plausible mechanisms that hypothetically link air pollution and adverse effects on human health (see Pope and Dockery (2006) and Pope et al. (2004)). Mortality from all circulatory diseases comprises the ICD-10 categories I00 to I99. Mortality from coronary heart disease is a subset of mortality from all circulatory diseases (ICD-10 categories I20 to I25). Mortality from acute myocardial infarction (heart attack), in turn, is a subset of mortality from coronary heart disease (ICD-10 I21 to I22). Mortality from stroke (ICD-10 I60-I69) is another subset of mortality from all circulatory diseases. Mortality from bronchitis, emphysema and other chronic obstructive pulmonary diseases consist of the categories J40 to J44, which are a subset of diseases of the respiratory system. The subset J40 to J44 excludes asthma, pneumonia and - most important - influenza, thus avoiding confounding of the pollutant effects by epidemics, which might coincide with increased air pollution. We use directly age-standardised rates to control for different population age structures across local authorities.

The time series plots of the standardised annual means of the six mortality rates in Figure 4 show a strong downward trend for the cardiovascular mortality rates. Many factors are likely to cause this fall, including the National Service Framework for Coronary Heart Disease (Department of Health 2000), a ten year plan initiated in 2000 with the aim of reducing coronary heart disease in the community. On the other hand, respiratory mortality has only a slight downward trend with peaks in 1999 and 2003. Consequently, the downward trend in mortality from all causes, which encompasses both cardiovascular and respiratory mortality, is less pronounced and levels off after 2001 before continuing in 2004.

The time-varying control variables in $\boldsymbol{Z}_{i t}$ in Equation 1 are the smoking rate, the employment rate, the percentage of working-age people who hold qualifications at degree level and above, the annual mean of summer daily maximum temperature and the annual mean of precipitation. Smoking is a strong predictor of premature mortality and an important source of indoor pollution. It is therefore important to control for smoking rates. Smoking rates are for 1998 and 2000 to 2005 for Government Office regions, which we match to the 354 local authorities in England. We interpolate rates for 1999. Employment rates proxy economic conditions, which may be correlated with health. In an analysis of US data, Ruhm (2000) shows that mortality rates fall when the economy temporarily deteriorates (though Gerdtham and Johannesson (2003) show that in Sweden unemployment increases the risk of dying). Education, in contrast, has a well established positive effect on health. We measure education 

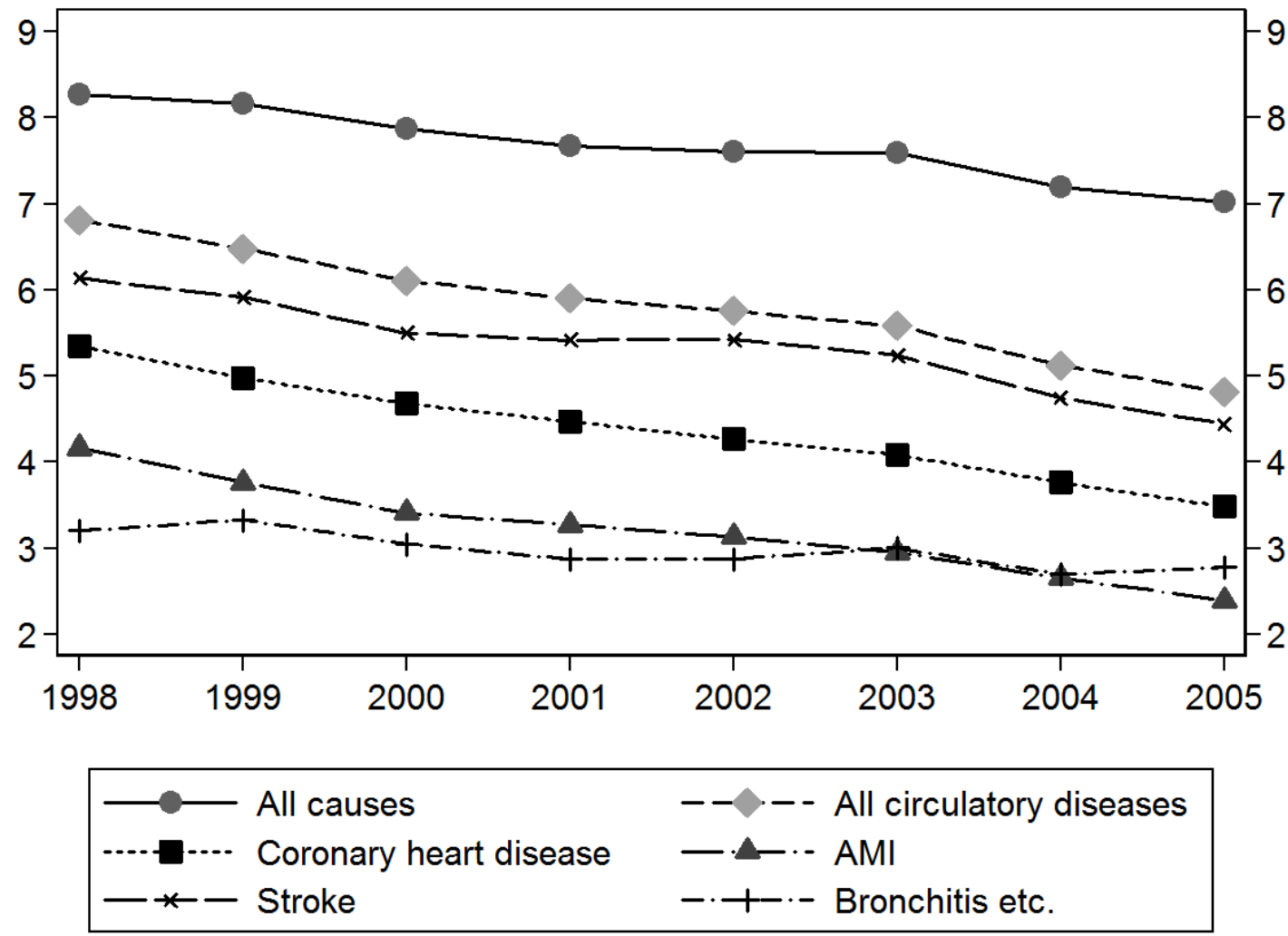

Figure 4: Standardised annual means of mortality rates. Standardisation by dividing annual means of a mortality rate by its standard deviation. Mortality from AMI (acute myocardial infarction) is a subset of mortality from coronary heart disease, which is a subset of mortality from all circulatory diseases. 
as the percentage of working-age people who hold qualifications at first degree level or higher.

The effects of air pollution could be confounded with weather conditions. ${ }^{14}$ To control for these, we use surface observation data on daily maximum temperatures and daily rainfall amounts, which we assign to the headquarters of the local authorities with the same procedure we use for the pollutants. Firstly, we calculate for all weather stations the annual means of precipitation and the annual means of the daily maximum temperature during the summer months April to September. Then we determine the distance of all stations to the headquarters of a local authority. Finally, we calculate weighted means of rainfall and temperature, using the annual means of all stations within a 10 miles radius and a 20 miles radius, respectively. The inverse of the distance between the headquarters and the weather station provides the weight. These measures should capture the effects of heat waves (for example, the summer of 2003) and very wet years.

The third panel in Table 1 presents descriptive statistics for the controls. Mean smoking rates fell from $27.4 \%$ in 1998 to $23.6 \%$ in 2005 , possibly reflecting the government's efforts to reduce smoking prevalence (Department of Health 1998). Mean employment rates and mean degree-level qualification rates increased between 1998 and 2005. Mean temperatures have increased during the sample period, with peaks in 1999 and 2003. Precipitation seems to have fallen, but the trend is less clear. As for the pollutants and the mortality rates, there is significant within local authority variation.

\section{$5 \quad$ Results}

\subsection{Cross-sectional associations}

Figure 5 maps the cross-sectional spatial distributions of mean all-cause mortality and mean local authority pollutant concentrations. Five different shades indicate the quintiles of the respective distribution. The figure shows a similar spatial distribution for three of the pollutants - $\mathrm{CO}, \mathrm{NO}_{2}$ and $\mathrm{PM}_{10}$ - which are higher in urban areas, while $\mathrm{O}_{3}$, is higher in rural areas. There is no clear north-south divide in this rural-urban split of pollution. In contrast, all-cause mortality shows a marked north-south split, death rates being higher in the north and lower in the more affluent south. So in the raw data, averaged over the sample period, there is little correspondence between the spatial distribution of mortality rates and of air pollutant concentrations.

Table 2 examines this further by reducing the information on variation shown in the maps to a split of the sample into terciles of the pollutant distributions and showing mean mortality from all causes across these terciles. There is some indication that higher concentrations of

\footnotetext{
${ }^{14}$ For instance, during heat waves, $\mathrm{O}_{3}$ levels rise because of the greater sunshine. Without controls for temperature, it may appear that $\mathrm{O}_{3}$ increases mortality, while in fact the heat caused excess deaths. On the other hand, to the extent that weather is associated with the level of pollution but does not have an independent effect on deaths, inclusion of weather variables will reduce the amount of variation in our pollution measures and make it more difficult to detect their effects.
} 

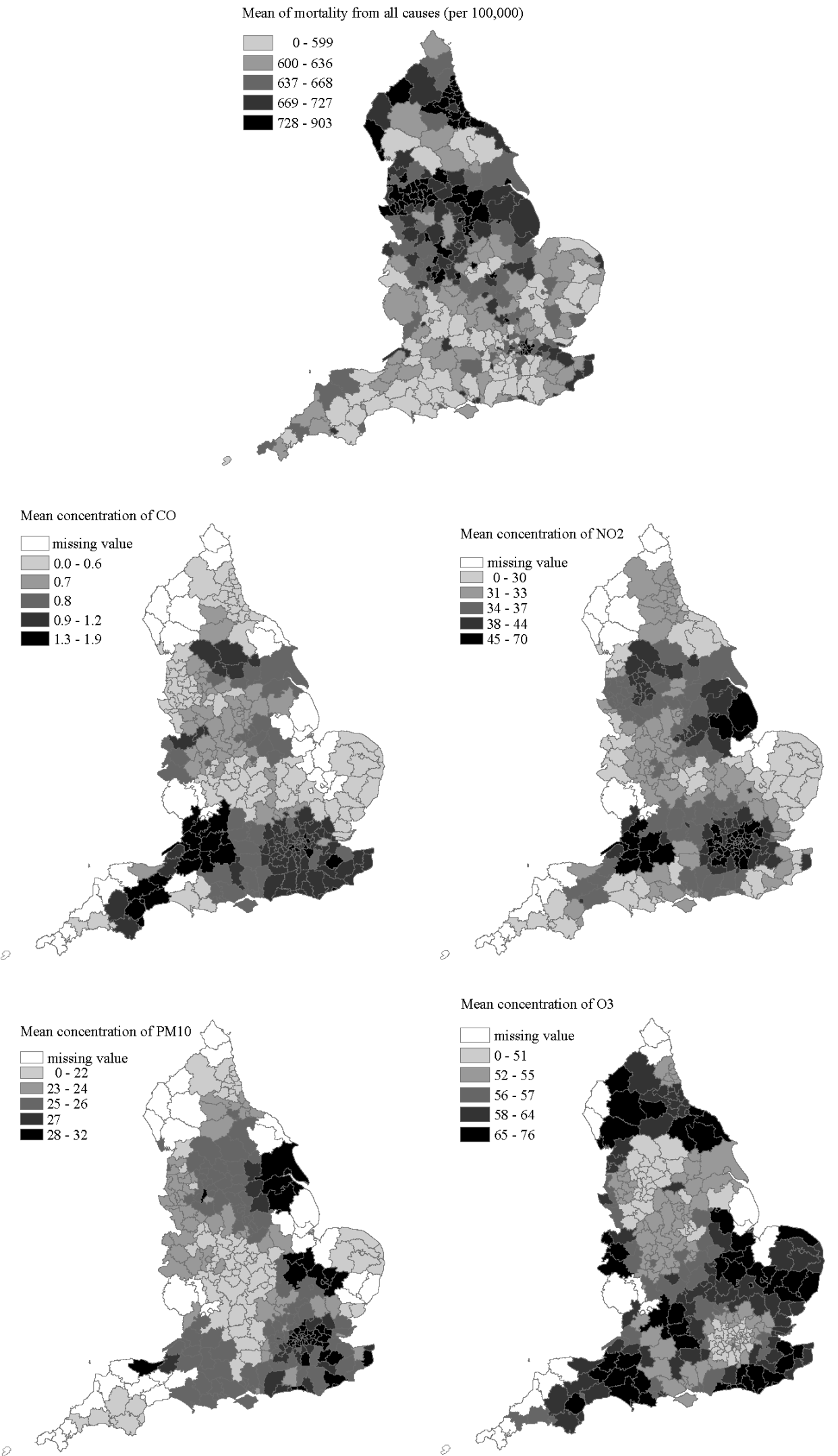

Figure 5: Cross-sectional distribution of mortality from all causes, $\mathrm{CO}, \mathrm{NO}_{2}, \mathrm{PM}_{10}$ and $\mathrm{O}_{3}$ 
$\mathrm{CO}$ and $\mathrm{NO}_{2}$ are associated with higher mortality rates. For example, the mean mortality rate for observations in the highest third of the $\mathrm{NO}_{2}$ distribution is $1.8 \%$ higher than the mean rate for the lowest third. The relationship, however, is not linear, with the mean rate for the middle third being greater than the mean rate for the highest third. In contrast, highest concentrations of $\mathrm{O}_{3}$ are associated with lower death rates. There is no clear relationship between $\mathrm{PM}_{10}$ and mortality, with the mean mortality rate for the middle third being smallest and the rates for the lowest and the highest third being similar.

Table 2: Means of pollutants and all-cause mortality by terciles of pollutant distributions for the estimation sample $(n=2,338)$

\begin{tabular}{llccc}
\hline \hline Ranked by & Variable & Lowest $1 / 3$ & Middle $1 / 3$ & Highest $1 / 3$ \\
\hline $\mathrm{CO}$ & $\mathrm{CO}\left(\mathrm{mg} / \mathrm{m}^{3}\right)$ & 0.5 & 0.7 & 1.2 \\
& Mortality from all causes (per 100,000) & 656.9 & 662.5 & 661.0 \\
& & & & \\
$\mathrm{NO}_{2}$ & $\mathrm{NO}_{2}\left(\mu \mathrm{g} / \mathrm{m}^{3}\right)$ & 27.5 & 35.1 & 47.3 \\
& Mortality from all causes (per 100,000) & 649.4 & 670.1 & 661.0 \\
& & & & \\
\multirow{2}{*}{$\mathrm{PM}_{10}$} & $\mathrm{PM}_{10}\left(\mu \mathrm{g} / \mathrm{m}^{3}\right)$ & 21.2 & 24.5 & 28.4 \\
& Mortality from all causes (per 100,000) & 662.4 & 654.1 & 663.9 \\
& & & & \\
$\mathrm{O}_{3}$ & $\mathrm{O}_{3}\left(\mu / \mathrm{m}^{3}\right)$ & 48.1 & 55.2 & 64.4 \\
& Mortality from all causes (per 100,000) & 686.6 & 656.8 & 634.7 \\
\hline \hline
\end{tabular}

\subsection{The relationship between each pollutant and all-cause mortality}

We start with an analysis of all-cause mortality to see if air pollution has any impact on this aggregate measure. We then focus on the specific causes of deaths for which the medical literature suggests they are causally related to air pollution (Pope et al. 2004). We begin by examining the separate association between each pollutant and mortality. The first column of Table 3 presents the raw correlations, estimated by an OLS regression of the log of all-cause mortality on a constant and the pollutant. We then control for trend, region and regionspecific trends and present OLS, within-group and three-year long-difference estimates. We then add the time-varying controls for weather and for lifestyle differences between local authorities. We multiply the outcome variable by 100 and divide the $\mathrm{NO}_{2}, \mathrm{PM}_{10}$ and $\mathrm{O}_{3}$ levels by 10 , so the coefficients are estimates of the percentage change in the mortality rate per $10 \mu \mathrm{g} / \mathrm{m}^{3}$ increase in $\mathrm{NO}_{2}, \mathrm{PM}_{10}$ or $\mathrm{O}_{3}$ or per $1 \mathrm{mg} / \mathrm{m}_{3}$ increase in CO.

The first block of Table 3 shows the estimates for CO. This shows no association between $\mathrm{CO}$ and all-cause mortality, apart from a slightly significant positive coefficient in the OLS equation with controls for time, region, weather and lifestyle, but this is not robust to the inclusion of local authority fixed effects. The second block shows the results for $\mathrm{NO}_{2}$. The raw association is positive but not significant. The coefficient estimates are significantly positive after controlling for trend and region, but adding the controls for lifestyle and weather makes 
Table 3: Estimates of the assocation between air pollutant concentrations and all-cause mortality rates in single-pollutant models. Dependent variable: $\ln$ (all-cause mortality) $\times 100$

\begin{tabular}{|c|c|c|c|c|c|c|c|}
\hline & \multirow[b]{2}{*}{ OLS } & $\overline{\overline{\text { OLS }}}$ & $\overline{\mathrm{WG}}$ & Long diff. & 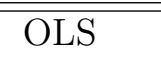 & $\overline{~ W G}$ & "Long diff. \\
\hline & & \multicolumn{3}{|c|}{$\begin{array}{l}\text { Controlling for trend, region } \\
\text { and regional trend }\end{array}$} & \multicolumn{3}{|c|}{$\begin{array}{l}\text { Trend, region, regional trend, } \\
\text { smoking rate, employment rate, } \\
\text { degree level qualification rate, } \\
\text { temperature and precipitation }\end{array}$} \\
\hline$\overline{\mathrm{CO}}$ & $\begin{array}{c}0.39 \\
(1.58)\end{array}$ & $\begin{array}{l}1.14 \\
(2.28)\end{array}$ & $\begin{array}{c}-0.13 \\
(0.61)\end{array}$ & $\begin{array}{c}-0.06 \\
(0.75)\end{array}$ & $\begin{array}{r}3.40^{*} \\
(1.74)\end{array}$ & $\begin{array}{r}-0.42 \\
(0.65)\end{array}$ & $\begin{array}{r}-0.90 \\
(0.77)\end{array}$ \\
\hline$R^{2}$ & 0.00 & 0.49 & 0.94 & 0.02 & 0.71 & 0.95 & 0.10 \\
\hline $\mathrm{NO}_{2} / 10$ & $\begin{array}{c}0.43 \\
(0.76)\end{array}$ & $\begin{array}{l}1.58^{* *} \\
(0.75)\end{array}$ & $\begin{array}{l}1.36^{* * *} \\
(0.24)\end{array}$ & $\begin{array}{l}1.40^{* * *} \\
(0.24)\end{array}$ & $\begin{array}{l}2.16^{* * *} \\
(0.49)\end{array}$ & $\begin{array}{c}0.42 \\
(0.27)\end{array}$ & $\begin{array}{c}0.21 \\
(0.25)\end{array}$ \\
\hline$R^{2}$ & 0.00 & 0.49 & 0.94 & 0.04 & 0.71 & 0.95 & 0.09 \\
\hline $\mathrm{PM}_{10} / 10$ & $\begin{array}{l}1.15 \\
(1.93)\end{array}$ & $\begin{array}{l}6.84^{* * *} \\
(1.50)\end{array}$ & $\begin{array}{l}4.07^{* * *} \\
(0.47)\end{array}$ & $\begin{array}{l}4.22^{* * *} \\
(0.51)\end{array}$ & $\begin{array}{l}3.96^{* * *} \\
(1.27)\end{array}$ & $\begin{array}{l}2.80^{* * *} \\
(0.51)\end{array}$ & $\begin{array}{l}2.38^{* * *} \\
(0.60)\end{array}$ \\
\hline$R^{2}$ & 0.00 & 0.50 & 0.94 & 0.07 & 0.71 & 0.95 & 0.11 \\
\hline $\mathrm{O}_{3} / 10$ & $\begin{array}{c}-5.04^{* * *} \\
(0.85)\end{array}$ & $\begin{array}{c}-0.86 \\
(0.85)\end{array}$ & $\begin{array}{l}1.92^{* * *} \\
(0.23)\end{array}$ & $\begin{array}{l}1.57^{* * *} \\
(0.26)\end{array}$ & $\begin{array}{c}-1.47^{* *} \\
(0.61)\end{array}$ & $\begin{array}{l}0.73^{* *} \\
(0.29)\end{array}$ & $\begin{array}{c}0.12 \\
(0.33)\end{array}$ \\
\hline$R^{2}$ & 0.08 & 0.49 & 0.94 & 0.05 & 0.71 & 0.95 & 0.09 \\
\hline Obs. & 2,338 & 2,338 & 2,338 & 1,404 & 2,338 & 2,338 & 1,404 \\
\hline Groups & 312 & 312 & 312 & 301 & 312 & 312 & 301 \\
\hline
\end{tabular}

$\overline{\mathrm{WG}=\text { within groups. Coefficients are percentage changes in all-cause mortality rate per } 1 \mathrm{mg} / \mathrm{m}^{3} \text { increase in CO }}$ and per $10 \mu \mathrm{g} / \mathrm{m}^{3}$ increase in $\mathrm{NO}_{2}, \mathrm{PM}_{10}$ and $\mathrm{O}_{3}$. Observations weighted by size of local authority population (mid-year population estimates). Robust standard errors in brackets. ${ }^{*}$ Significant at $10 \%$, ${ }^{*}$ significant at $5 \%$, *** significant at $1 \%$ 
the within-group and long-difference estimates insignificant. The results for $\mathrm{PM}_{10}$ in the third block show a positive but insignificant raw association and significantly positive coefficients for all other specifications. The within-group and long-difference estimates are similar. The within-group estimate suggests that a $10 \mu \mathrm{g} / \mathrm{m}^{3}$ increase in $\mathrm{PM}_{10}$ is associated with a $2.8 \%$ increase in all-cause mortality.

The final block shows the results for $\mathrm{O}_{3}$. The raw correlation is negative and significant, showing the association seen in Figure 5: rural areas, which have lower mortality rates, have higher $\mathrm{O}_{3}$ concentrations. Adding time varying controls does not change this negative sign, though the point estimate is considerably smaller. Allowing for local authority fixed effects, however, changes the direction of the association. Both the within-groups and the longdifference estimates indicate a positive effect of $\mathrm{O}_{3}$ on all-cause mortality. The within-groups point estimate is a $0.7 \%$ increase in all-cause mortality for a $10 \mu \mathrm{g} / \mathrm{m}^{3}$ increase in $\mathrm{O}_{3}$.

\subsection{The relationship between all pollutants simultaneously and all-cause mortality}

Table 4 repeats the analyses of Table 3, but includes all pollutants simultaneously to allow for correlation between the pollutant levels. It confirms that $\mathrm{CO}$ has no independent effect on death rates. For $\mathrm{NO}_{2}$ the within-group and long-difference estimates are again significantly positive when controlling only for trend, region and regional trend, but become insignificant when adding the controls for lifestyle and weather.

The coefficient on $\mathrm{PM}_{10}$ remains significantly positive in all specifications, though it falls by 2 to $40 \%$. The within-group estimate from the specification with all controls suggests that per $10 \mu \mathrm{g} / \mathrm{m}^{3}$ increase in $\mathrm{PM}_{10}$ the all-cause mortality rate increases by $2.7 \%$. The corresponding long-difference estimate suggests an impact of $2.4 \%$, not significantly below the within-group estimate. The associations between $\mathrm{O}_{3}$ and mortality in the multi-pollutant model are similar to those estimated by the single-pollutant model, though the negative coefficient estimate in the OLS specification with all controls becomes insignificant. Using the within-group specification with all controls, the estimated impact of $\mathrm{O}_{3}$ is $0.8 \%$ per 10 $\mu \mathrm{g} / \mathrm{m}^{3}$ increase. The corresponding long-difference estimate is not significantly different from zero. However, the long-difference sample is much smaller, so the effect of O3 might be masked by the control for summer temperatures in this smaller sample. We therefore give more credence to the within-group estimates. ${ }^{15}$

The association of the controls with all-cause mortality are shown in the final three columns of Table 4. As expected, smoking rates are positively associated with higher death rates. The estimate, however, is (marginally) significant only in the OLS specification. The employment rate and the degree-level qualification rate are negatively associated with death rates, but

\footnotetext{
${ }^{15}$ Estimates using differences two periods apart support this argument, as they are closer to the within-group estimates. The point estimates are, in fact, larger than the within-group estimates: $\mathrm{NO}_{2} 0.59$ (s.e. = 0.28), $\mathrm{PM}_{10} 2.50($ s.e. $=0.63), \mathrm{O}_{3} 0.81$ (s.e. $\left.=0.32\right), 1,701$ observations, 304 groups.
} 
Table 4: Estimates of the assocation between air pollutant concentrations and all-cause mortality rates in multi-pollutant models. Dependent variable: $\ln ($ all-cause mortality) $\times 100$

\begin{tabular}{|c|c|c|c|c|c|c|c|}
\hline & \multirow[b]{2}{*}{ OLS } & OLS & $\overline{\mathrm{WG}}$ & Long diff. & OLS & $\overline{~ W G}$ & Long diff. \\
\hline & & \multicolumn{3}{|c|}{$\begin{array}{l}\text { Controlling for trend, region } \\
\text { and regional trend }\end{array}$} & \multicolumn{3}{|c|}{$\begin{array}{l}\text { Trend, region, regional trend, } \\
\text { smoking rate, employment rate, } \\
\text { degree level qualification rate, } \\
\text { temperature and precipitation }\end{array}$} \\
\hline $\mathrm{CO}$ & $\begin{array}{c}0.45 \\
(1.63)\end{array}$ & $\begin{array}{c}-2.27 \\
(2.30)\end{array}$ & $\begin{aligned}-0.39 \\
(0.72)\end{aligned}$ & $\begin{array}{c}-0.79 \\
(0.80)\end{array}$ & $\begin{array}{c}0.27 \\
(1.68)\end{array}$ & $\begin{array}{c}-0.34 \\
(0.69)\end{array}$ & $\begin{array}{c}-0.94 \\
(0.78)\end{array}$ \\
\hline $\mathrm{NO}_{2} / 10$ & $\begin{array}{l}-2.82^{* * *} \\
(0.94)\end{array}$ & $\begin{array}{c}0.49 \\
(0.75)\end{array}$ & $\begin{array}{l}0.64^{* *} \\
(0.27)\end{array}$ & $\begin{array}{l}0.64^{* * *} \\
(0.24)\end{array}$ & $\begin{array}{l}1.50^{* *} \\
(0.62)\end{array}$ & $\begin{array}{c}0.34 \\
(0.28)\end{array}$ & $\begin{array}{c}0.17 \\
(0.26)\end{array}$ \\
\hline $\mathrm{PM}_{10} / 10$ & $\begin{array}{l}1.85 \\
(1.92)\end{array}$ & $\begin{array}{l}6.72^{* * *} \\
(1.55)\end{array}$ & $\begin{array}{l}3.03^{* * *} \\
(0.47)\end{array}$ & $\begin{array}{l}3.36^{* * *} \\
(0.52)\end{array}$ & $\begin{array}{r}2.33^{*} \\
(1.37)\end{array}$ & $\begin{array}{l}2.74^{* * *} \\
(0.51)\end{array}$ & $\begin{array}{l}2.37^{* * *} \\
(0.59)\end{array}$ \\
\hline $\mathrm{O}_{3} / 10$ & $\begin{array}{c}-6.60^{* * *} \\
(0.80)\end{array}$ & $\begin{array}{c}-0.59 \\
(0.80)\end{array}$ & $\begin{array}{l}1.57^{\text {*** }} \\
(0.24)\end{array}$ & $\begin{array}{l}1.06^{* * *} \\
(0.27)\end{array}$ & $\begin{array}{r}-0.55 \\
(0.66)\end{array}$ & $\begin{array}{l}0.80^{* * *} \\
(0.29)\end{array}$ & $\begin{array}{c}0.18 \\
(0.34)\end{array}$ \\
\hline $\begin{array}{l}\text { Smoking } \\
\text { rate }\end{array}$ & & & & & $\begin{array}{c}0.18^{*} \\
(0.10)\end{array}$ & $\begin{array}{c}0.07 \\
(0.08)\end{array}$ & $\begin{array}{c}0.20 \\
(0.13)\end{array}$ \\
\hline $\begin{array}{l}\text { Employm. } \\
\text { rate }\end{array}$ & & & & & $\begin{array}{c}-0.80^{* * *} \\
(0.06)\end{array}$ & $\begin{array}{c}0.00 \\
(0.04)\end{array}$ & $\begin{array}{c}0.05 \\
(0.04)\end{array}$ \\
\hline $\begin{array}{l}\text { Degree } \\
\text { qual. rate }\end{array}$ & & & & & $\begin{array}{l}-0.46^{* * *} \\
(0.07)\end{array}$ & $\begin{array}{r}-0.06^{*} \\
(0.03)\end{array}$ & $\begin{array}{c}-0.04 \\
(0.03)\end{array}$ \\
\hline Summer & & & & & $0.96^{* *}$ & $0.90^{* * *}$ & $0.94^{* * *}$ \\
\hline temp. & & & & & $(0.39)$ & $(0.20)$ & $(0.23)$ \\
\hline Precip- & & & & & $1.30^{* *}$ & 0.46 & -0.12 \\
\hline itation & & & & & $(0.54)$ & $(0.35)$ & $(0.36)$ \\
\hline$\overline{R^{2}}$ & 0.10 & 0.50 & 0.95 & 0.09 & 0.71 & 0.95 & 0.11 \\
\hline Obs. & 2,338 & 2,338 & 2,338 & 1,404 & 2,338 & 2,338 & 1,404 \\
\hline Groups & 312 & 312 & 312 & 301 & 312 & 312 & 301 \\
\hline
\end{tabular}

$\mathrm{WG}=$ within groups. Coefficients are percentage changes in all-cause mortality rate per $1 \mathrm{mg} / \mathrm{m}^{3}$ increase in CO and per $10 \mu \mathrm{g} / \mathrm{m}^{3}$ increase in $\mathrm{NO}_{2}, \mathrm{PM}_{10}$ and $\mathrm{O}_{3}$. Observations weighted by size of local authority population (mid-year population estimates). Robust standard errors in brackets. ${ }^{*}$ Significant at $10 \%,{ }^{* *}$ significant at $5 \%$, *** significant at $1 \%$ 
the coefficients are significant only in the OLS specification, indicating that these variables are capturing unobserved differences between local authorities rather than the effect of time variation in employment and education on death rates. ${ }^{16}$

\subsection{The relationship between pollutants and specific causes of mortality}

The medical literature suggests that the association between air pollution and mortality is driven by deaths from cardiovascular and respiratory causes (see, for example, Bell et al. (2005) and Pope et al. (2002)). Several pathophysiological pathways that link particulate matter and mortality from cardiovascular diseases have been suggested (see Pope and Dockery (2006) and Department of Health (2006)). The two main hypotheses are the clotting hypothesis and the neural hypothesis. ${ }^{17}$ From the first, we would expect to find positive associations between $\mathrm{PM}_{10}$ and mortality from coronary heart disease in particular, but also stroke, heart failure and atherosclerosis (Pope et al. 2004). Therefore, we examine mortality from all circulatory diseases, coronary heart disease, acute myocardial infarction (heart attack) and stroke. Data on mortality from heart failure and atherosclerosis on local authority level are not publicly available. We are not able to examine the pathways suggested by the neural hypothesis.

Table 5 presents these estimates. The first column repeats the within-group estimates for all-cause mortality from Table 4 for comparison. The results show that $\mathrm{PM}_{10}$ is positively associated with all four cardiovascular mortality rates. We find a large and highly significant positive effect on mortality from coronary heart disease (a subset of mortality from all circulatory diseases), for which we should find a strong effect according to the clotting hypothesis. The estimates suggest that a $10 \mu \mathrm{g} / \mathrm{m}^{3}$ increase in $\mathrm{PM}_{10}$ increases each of the four specific mortality rates by around 4 to $5 \% . \mathrm{O}_{3}$ is positively associated with mortality from bronchitis, emphysema and other chronic obstructive pulmonary diseases, suggesting that the association between $\mathrm{O}_{3}$ and mortality is driven by mortality from respiratory causes. The coefficient is significant at the $10 \%$ level only, perhaps because the relatively small death rates (around 30 per 100,000 population) do not allow the effect to be estimated precisely enough.

Thus, we find that pollution levels are associated with those specific causes of death that are indicated in the literature on the pathways by which pollution leads to death. Further,

\footnotetext{
${ }^{16} \mathrm{We}$ also tested the robustness of our results to defining economic activity in terms of unemployment instead of employment and to inclusion of an additional control for local pay rates (the log of the average male pay). We found very similar results: no measures of economic conditions were significantly associated with all-cause mortality in models which controlled for local authority fixed effects.

${ }^{17}$ The clotting hypothesis suggests that particles penetrating into the lungs cause an inflammatory response in the lungs. The inflammation in turn might trigger changes in the control of blood clotting, causing, for example, thrombosis. Alternatively, the inflammation might change chemical factors in the blood that affect the stability of the atheromatous plaques in the arteries that supply blood to the heart muscle. The atheromatous plaques might rupture, causing a blockage of the artery. The neural hypothesis proposes that inhaled particles might trigger a reflex that leads to subtle changes in the heart rhythm, making the heart more susceptible to dangerous changes in the rhythm that potentially cause sudden death. Therefore, we would expect to find positive associations between particulate matter and mortality from dysrhythmias, heart failure and cardiac arrest (Pope et al. 2004). Data on mortality from these causes on local authority level are not publicly available, so we cannot examine this potential pathway.
} 
Table 5: Within-group estimates of the associaton between air pollutant concentrations and a range of mortality rates in a multi-pollutant model. Dependent variable: $\ln$ (mortality rate) $\times 100$

\begin{tabular}{lcccccc}
\hline \hline & All causes & $\begin{array}{c}\text { All cir- } \\
\text { culatory } \\
\text { diseases }\end{array}$ & $\begin{array}{c}\text { Coronary } \\
\text { heart } \\
\text { disease }\end{array}$ & $\begin{array}{c}\text { Acute } \\
\text { myocardial } \\
\text { infarction }\end{array}$ & Stroke & $\begin{array}{c}\text { Bronchitis, } \\
\text { emphysema, } \\
\text { other COPD }\end{array}$ \\
\hline $\mathrm{CO}$ & -0.34 & -0.02 & 1.18 & -1.51 & -3.18 & -3.82 \\
$\mathrm{NO}_{2} / 10$ & $(0.69)$ & $(1.53)$ & $(1.27)$ & $(2.36)$ & $(4.04)$ & $(3.51)$ \\
& 0.34 & 0.34 & 0.27 & -1.91 & 0.82 & 1.91 \\
$\mathrm{PM}_{10} / 10$ & $(0.28)$ & $(0.49)$ & $(0.65)$ & $(1.27)$ & $(0.91)$ & $(1.27)$ \\
& $2.74^{* * *}$ & $4.38^{* * *}$ & $4.90^{* * *}$ & $5.03^{* *}$ & $4.08^{* *}$ & 1.80 \\
$\mathrm{O}_{3} / 10$ & $(0.51)$ & $(0.78)$ & $(1.05)$ & $(2.09)$ & $(1.78)$ & $(2.49)$ \\
& $0.80^{* * *}$ & -0.01 & -0.39 & -1.37 & 0.02 & $2.40^{*}$ \\
\hline$R^{2}$ & $(0.29)$ & $(0.54)$ & $(0.69)$ & $(1.18)$ & $(0.90)$ & $(1.23)$ \\
Obs. & 0.95 & 0.92 & 0.91 & 0.86 & 0.76 & 0.83 \\
Groups & 2,338 & 2,338 & 2,338 & 2,338 & 2,338 & 2,338 \\
\hline \hline
\end{tabular}

COPD $=$ chronic obstructive pulmonary diseases. Coefficients are percentage changes in all-cause mortality rate per $1 \mathrm{mg} / \mathrm{m}^{3}$ increase in $\mathrm{CO}$ and per $10 \mu \mathrm{g} / \mathrm{m}^{3}$ increase in $\mathrm{NO}_{2}, \mathrm{PM}_{10}$ and $\mathrm{O}_{3}$. Controls are trend, regionspecific trends, smoking rate, employment rate, degree-level qualification rate, annual mean of daily maximum temperature in summer and annual mean of precipitation. Observations are weighted by the size of the local authority population (mid-year population estimates). Robust standard errors in brackets. ${ }^{*}$ Significant at $10 \%$, $* *$ significant at $5 \%, * * *$ significant at $1 \%$

our estimates suggest that the effects of pollution on these specific causes of death account for a high fraction of the estimated effect of pollution on all-cause mortality. Using the sample mean for each specific mortality rate from Table 1 and applying our estimates from Table 5, the overall estimated effect of $\mathrm{PM}_{10}$ on coronary heart disease and stroke accounts for $80 \%$ of our estimated effect of $\mathrm{PM}_{10}$ on all circulatory diseases, while the effect on mortality from circulatory disease accounts for $60 \%$ of our estimated effect on all deaths.

\subsection{The relationship between all pollutants and all-cause mortality for different age groups}

The literature suggests that children and elderly persons are most likely to be susceptible to air pollution (Pope and Dockery 2006). So if our results indicate some causal link, we should find greater effects for these age groups. Table 6 presents within-group estimates of the association between air pollutants and all-cause mortality by broad age groups: under 15 years, between 15 to 64 years, 65 to 74 years and older than 75 years. As directly age-standardised rates are not publicly available for the older than 75 years group, we use non-age-standardised data and control for population age structure by including controls for proportions of age groups in 5 -year age bands on the right-hand side. ${ }^{18}$

\footnotetext{
${ }^{18}$ This specification is on a per capita basis, so also acts as a robustness check of our use of age-standardised mortality rates; see also Row 12 of Table 7.
} 
Table 6: Within-group estimates of the association between air pollutant concentrations and all-cause mortality for different age groups in a multi-pollutant model. Dependent variable:

\begin{tabular}{lccccc}
\multicolumn{5}{c}{$\ln ($ mortality rate $) \times 100$} \\
\hline \hline $\mathrm{CO}$ & All ages & $<15$ & $15-64$ & $65-74$ & $>75$ \\
& $-1.02^{*}$ & 5.08 & $2.65^{* *}$ & -1.05 & $-1.60^{*}$ \\
$\mathrm{NO}_{2} / 10$ & $(0.56)$ & $(5.57)$ & $(1.18)$ & $(1.13)$ & $(0.85)$ \\
& $0.72^{* *}$ & -1.77 & -0.25 & 0.88 & $0.82^{* *}$ \\
$\mathrm{PM}_{10} / 10$ & $(0.29)$ & $(2.68)$ & $(0.61)$ & $(0.58)$ & $(0.37)$ \\
& $2.46^{* * *}$ & $9.30^{* *}$ & $2.27^{* *}$ & 1.63 & $3.14^{* * *}$ \\
$\mathrm{O}_{3} / 10$ & $(0.53)$ & $(4.57)$ & $(1.05)$ & $(1.00)$ & $(0.64)$ \\
& $0.69^{* *}$ & 2.41 & -0.12 & 0.51 & $0.90^{* * *}$ \\
& $(0.29)$ & $(2.34)$ & $(0.60)$ & $(0.54)$ & $(0.32)$ \\
\hline$R^{2}$ & 0.97 & 0.52 & 0.88 & 0.91 & 0.80 \\
Observations & 2,338 & 2,331 & 2,338 & 2,338 & 2,338 \\
Groups & 312 & 312 & 312 & 312 & 312 \\
\hline \hline
\end{tabular}

Coefficients are percentage changes in all-cause mortality rate per $1 \mathrm{mg} / \mathrm{m}^{3}$ increase in CO and per $10 \mu \mathrm{g} / \mathrm{m}^{3}$ increase in $\mathrm{NO}_{2}, \mathrm{PM}_{10}$ and $\mathrm{O}_{3}$. Mortality rates are not age-standardised. Controls are proportions of age groups ( 5 year age bands), trend, region-specific trends, smoking rate, employment rate, degree-level qualification rate, annual mean of daily maximum temperature in summer and annual mean of precipitation. Observations weighted by size of the local authority population for respective age group. Robust standard errors in brackets. ${ }^{*}$ Significant at $10 \%,{ }^{* *}$ significant at $5 \%, * * *$ significant at $1 \%$

For comparison, the first column of Table 6 presents estimates for all ages using the all-cause mortality rate that is not age-standardised. The coefficients are similar to those obtained using age-standardised rates. Columns 2 to 5 of Table 6 show that the effects of $\mathrm{PM}_{10}$ and $\mathrm{O}_{3}$ are largest for the most vulnerable groups. The $\mathrm{PM}_{10}$ estimates are largest for the youngest age group. The absolute impact is smaller, because of the very low death rates in this age group. At the mean of the under 15 years old mortality rate, 44 per 100,000, a 10 $\mu / \mathrm{m}^{3}$ increase in $\mathrm{PM}_{10}$ increases the number of deaths by 4 , whereas the coefficient estimate for the over 75 years old suggests that at the mean mortality rate of 10,556 per 100,000 a $10 \mu \mathrm{g} / \mathrm{m}^{3}$ increase in $\mathrm{PM}_{10}$ increases the number of deaths by 331 . The coefficient on $\mathrm{O}_{3}$ is significant only for the over 75 years old, suggesting that the coefficient estimate for $\mathrm{O}_{3}$ in the all-ages specification is driven by this age group. Disaggregation by age also shows an effect of $\mathrm{NO}_{2}$ (again for the elderly) and for $\mathrm{CO}$ (in this case for those aged 15 to 64).

\section{$6 \quad$ Robustness checks}

Our method involves assignation of air pollution levels to local authorities and the estimation of a linear relationship between pollution and death rates. We subject these assumptions to robustness tests. We further explore whether our results are indicative of a causal relationship by first undertaking 'placebo tests' and second by examining whether confounding factors could account for the association we find between pollution and mortality. The results of our robustness tests are summarized in Table 7 . The baseline estimates in row 1 are the 
within-group estimates from the specification with all four pollutants simultaneously and the full set of controls in the last block of Table 4 .

\subsection{The assignation of air pollution to areas}

Our air pollution measure is the distance-weighted mean of the annual mean pollutant concentrations at monitors within a 30 mile radius (10 miles for London) of the headquarters of a local authority. Row 2 of Table 7 presents estimates using a 20 mile radius $(5$ miles for London). The number of local authorities to which we can assign an air pollution measure drops from 312 to 267 . The coefficients on $\mathrm{PM}_{10}$ and $\mathrm{O}_{3}$ fall by $20 \%$ and $5 \%$, respectively, but they are still significantly positive.

To calculate our air pollution measures we used monitoring stations that are situated in different environments, for example in urban areas, at roadsides or in rural areas. If a local authority has mainly roadside or kerbside monitoring stations, actual exposure might be lower than our measures suggest. Row 3 of Table 7 examines robustness of our results when we omit readings from kerbside and roadside stations. The number of local authorities to which we can assign a pollution measure drops from 312 to 243 . Though the coefficients on $\mathrm{PM}_{10}$ and $\mathrm{O}_{3}$ drop by $20 \%$ and $5 \%$, respectively, they are still significantly positive.

The summer of 2003 was unusually hot. This was also a year with higher death rates and higher $\mathrm{O}_{3}$ and $\mathrm{PM}_{10}$ levels. Row 4 examines the robustness of our results to omission of this year. The estimated impact of both $\mathrm{PM}_{10}$ and $\mathrm{O}_{3}$ falls by around a third, as might be expected given this year is an outlier, but $\mathrm{PM}_{10}$ remains well defined. ${ }^{19}$ More generally, to test that our results are not driven by areas with high levels of pollution which may not be representative of England, we omit observations with one or more pollutants in the top $10 \%$ of the pollutant distribution. Row 5 shows that the results are robust to this omission.

Our assignment of pollution measures to local authorities is based on distance to monitoring stations, without taking into account wind direction, which is predominantly from the west in England. Local authorities located in the South West, in particular, will have measures predominantly based on stations to their east. To examine whether this is a problem, Row 6 omits observations in the South West. Our results are little affected by omitting this region.

Air pollution - at least from $\mathrm{CO}, \mathrm{NO}_{2}$ and $\mathrm{PM}_{10}$ - might be an urban phenomenon. We therefore checked that our results were not solely due to London by omitting all London observations. Row 7 shows that the estimates for $\mathrm{PM}_{10}$ and $\mathrm{O}_{3}$ fall by around $20 \%$ but remain

\footnotetext{
${ }^{19}$ If we allow for a full set of year dummies the coefficient on $\mathrm{PM}_{10}$ falls to 1.12 (s.e. $\left.=0.54\right)$ and the coefficient on $\mathrm{O}_{3}$ falls to -0.24 (s.e. $=0.32$ ). However, both weather coefficients have incorrect signs (the coefficient on hot weather is significantly negative and the coefficient on precipitation is positive and significant) and several of the year dummies are not significantly different from each other. We conclude that we cannot identify separate year, pollution and weather effects. A more parsimonious time specification that fits the time pattern in death rates (a spline with knots in 1999 and 2003, both of which are years with higher death rates and higher temperatures) gives significant positive coefficients for both pollutants and summer temperature $\left(\mathrm{PM}_{10} 2.18\right.$ $($ s.e. $=0.55), \mathrm{O}_{3} 0.80($ s.e. $=0.29)$, summer temperature $0.66($ s.e. $=0.20)$ ).
} 


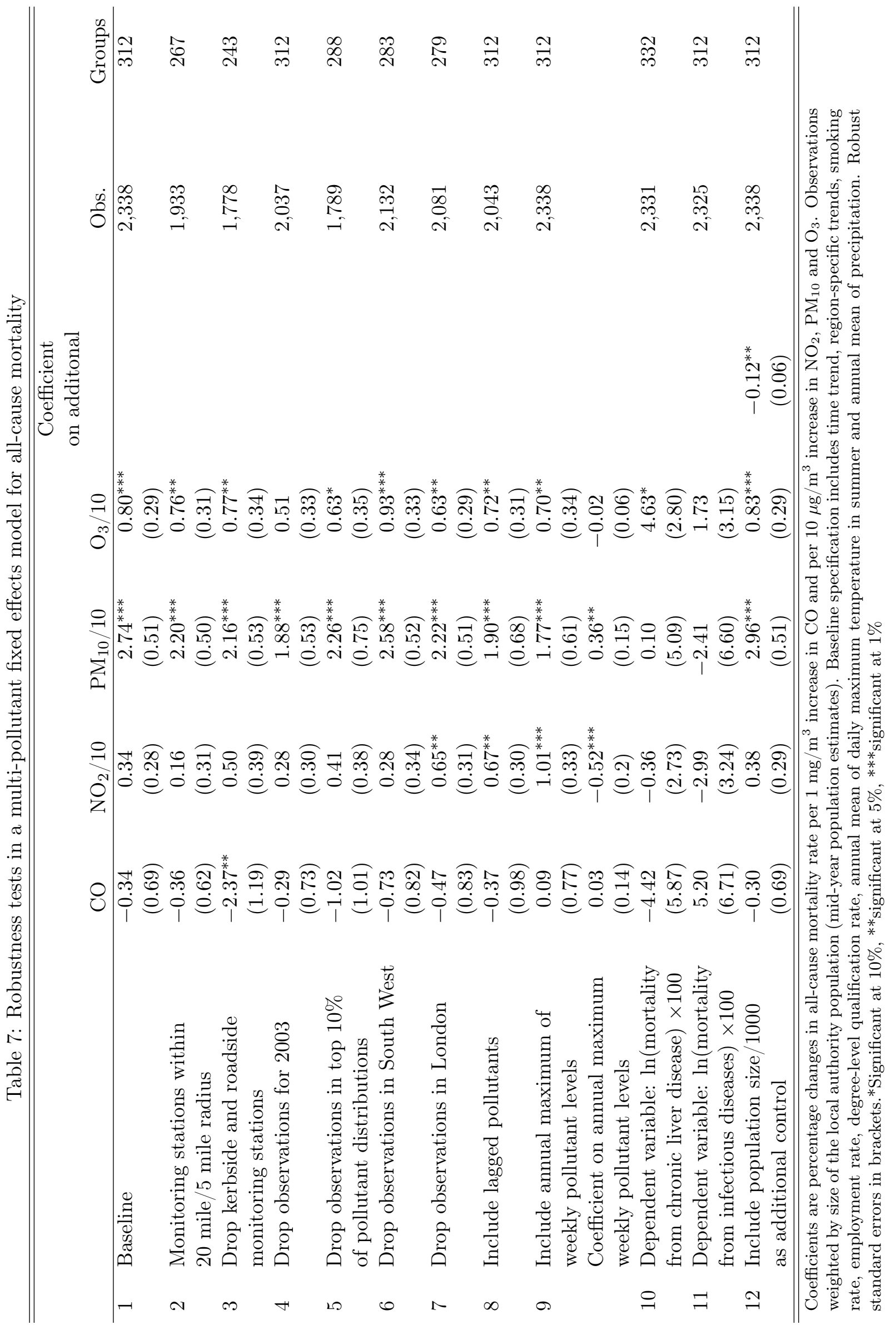


significantly positive. The estimate for $\mathrm{NO}_{2}$ increases by $30 \%$ and becomes significantly positive. ${ }^{20}$

\subsection{Dynamics and non-linearities}

We were concerned that we might have mis-specified the dynamic structure of the model. Row 8 therefore includes the lagged levels as well as the current levels of the pollutants. The estimated effects of current $\mathrm{PM}_{10}$ and $\mathrm{O}_{3}$ change slightly but remain statistically significant. ${ }^{21}$ We also conditioned on lagged mortality. Again, our results were robust to this, suggesting that the local authority fixed effects do a good job of picking up unobserved heterogeneity between local authorities.

Our model assumes that the impact of air pollution on mortality is linear. We investigate non-linearities using splines in the levels of $\mathrm{PM}_{10}$ and $\mathrm{O}_{3}$ in a within-group specification controlling for $\mathrm{CO}, \mathrm{NO}_{2}$, trend, region-specific trends and our full set of covariates. We place two knots at the $33^{\text {rd }}$ and $66^{\text {th }}$ percentiles, dividing the pollutant data into terciles. Table 8 presents the results. For $\mathrm{PM}_{10}$ the coefficients for the middle tercile and the highest tercile are larger than the coefficient for the lowest tercile, though the relationship is not linear, with the largest estimate for the middle tertile. For $\mathrm{O}_{3}$ there seems to be a negative relationship, with the coefficient for the lowest tercile being larger than the coefficient for the middle tercile and the coefficient for the middle tercile being larger then coefficient for the highest tercile. The estimates for the middle and the highest tercile, however, are not significantly different from zero.

We also tested whether the annual maxima of the weekly means of the pollutant concentrations have an impact on mortality to determine whether the long-term average level of air pollution or short-term peaks drive the relationship between air pollution and mortality. Row 9 in Table 7 presents the results. The first line shows the coefficients for the annual mean pollutant concentrations, the second line the coefficients for the annual maxima of the weekly mean pollutant concentrations. The coefficient for the annual mean level of $\mathrm{PM}_{10}$ drops by around one third, but is still significantly positive. The level of $\mathrm{PM}_{10}$ in the week with the highest $\mathrm{PM}_{10}$ level is positively associated with the annual mortality rate, though the size of the effect is only one fifth of the effect of the annual mean level of $\mathrm{PM}_{10}$. The

\footnotetext{
${ }^{20}$ We also checked if there are regional differences in the impact of $\mathrm{PM}_{10}$ on mortality. The region pattern is quite complex, but there is a group of regions where the impact of $\mathrm{PM}_{10}$ is largest, both for all-cause mortality and the specific mortality rates. These regions are South West, East Midlands and North East.

${ }^{21}$ The coefficients on the lagged pollutants are small and insignificant for three of the four pollutants. For $\mathrm{O}_{3}$, however, the coefficient on the lag is similar and of opposite sign to that of current $\mathrm{O}_{3}$. This result might indicate that the impact of $\mathrm{O}_{3}$ is to bring mortality that would have otherwise occurred forward (harvesting). Conditional on a positive association with the current level of pollution, a negative coefficient on the lagged level could indicate harvesting, since individuals who died last year are not available to die this year. However, the issue of harvesting has less force for annual data as - by definition - the mortality rates and the measures of pollution average out short run increase and decreases. In our data, years with higher than average $\mathrm{O}_{3}$ are preceded by years with lower than average $\mathrm{O}_{3}$ : it seems likely that in this short time series this is what the lagged coefficient is picking up.
} 
Table 8: Within-group estimates of the association between air pollutant concentrations and all-cause mortality using a spline with knots at the $33^{\text {rd }}$ and $66^{\text {th }}$ percentile

\begin{tabular}{lccc}
\hline \hline Pollutant & Lowest tercile & Middle tercile & Highest tercile \\
\hline $\mathrm{CO}$ & $2.24^{* *}$ & $3.48^{* * *}$ & $2.69^{* * *}$ \\
& $(1.05)$ & $(1.13)$ & $(0.69)$ \\
$\mathrm{NO}_{2}$ & $0.97^{* *}$ & 0.88 & 0.62 \\
& $(0.49)$ & $(0.54)$ & $(0.45)$ \\
\hline \hline
\end{tabular}

Coefficients are percentage changes in all-cause mortality rate per $1 \mathrm{mg} / \mathrm{m}^{3}$ increase in CO and per $10 \mu \mathrm{g} / \mathrm{m}^{3}$ increase in $\mathrm{NO}_{2}, \mathrm{PM}_{10}$ and $\mathrm{O}_{3}$. Controls are $\mathrm{CO}, \mathrm{NO}_{2}$, time trend, region-specific trends, smoking rate, employment rate, degree-level qualification rate, annual mean of daily maximum temperature in summer and annual mean of precipitation. Observations weighted by size of the local authority population (mid-year population estimates). Robust standard errors in brackets. ${ }^{*}$ Significant at $10 \%,{ }^{* *}$ significant at $5 \%,{ }^{* * *}$ significant at $1 \%$

coefficient for the annual mean level of $\mathrm{O}_{3}$ drops by less than $10 \%$, and the coefficient for the maximum weekly level of $\mathrm{O}_{3}$ is not significantly different from zero. The coefficient for annual mean $\mathrm{NO}_{2}$ becomes significantly positive, but the coefficient for maximum weekly $\mathrm{NO}_{2}$ has an unexpected negative sign and largely offsets the effect of annual mean $\mathrm{NO}_{2}$, leaving the joint effect similar to the baseline estimate. ${ }^{22}$ These tests show that there is some evidence of non-linear effects, but they do not change our main finding that $\mathrm{PM}_{10}$ and $\mathrm{O}_{3}$ are positively associated with mortality.

\subsection{Placebo tests}

It is possible that the association of mortality with pollution does not result from pollution effects, but that our pollution measures are proxies for some omitted factor which is correlated with pollution but itself is the cause of deaths. To some extent, this is already dealt with by using local authority fixed effects and region-specific time trends. Any non-time-varying factors - such as poor health care services or the presence of health risks in urban settings will be controlled for by the fixed effects, and the region-specific trends will pick up changes over time at regional level. However, it is possible that there are omitted time-varying factors at local authority level that are correlated with changes in pollution and that are driving our results.

One way of testing for this is to examine mortality from causes that are unlikely to be affected by the within local authority time series variation in pollution. If the coefficients for the air pollutants are similar to those found in the baseline specification, then this suggests that some omitted factor may be driving the association we find between air pollution and mortality rates. Two candidate causes are chronic liver disease (including cirrhosis) and infectious and parasitic diseases. Rows 10 and 11 report the coefficients on the pollutants

\footnotetext{
${ }^{22}$ The somewhat odd results for $\mathrm{NO}_{2}$ may be due to collinearity. In fact, annual mean $\mathrm{NO}_{2}$ and maximum weekly $\mathrm{NO}_{2}$ are strongly correlated, with $\mathrm{r}=0.86$. The correlation coefficients for the other pollutants are smaller: annual mean $\mathrm{CO}$ and maximum weekly $\mathrm{CO}: \mathrm{r}=0.65$, annual mean $\mathrm{PM}_{10}$ and maximum weekly $\mathrm{PM}_{10}: \mathrm{r}=0.65$, annual mean $\mathrm{O}_{3}$ and maximum weekly $\mathrm{O}_{3}: \mathrm{r}=0.57$.
} 
for the baseline specification with age-standardised mortality rates from liver disease and infectious and parasitic diseases as the dependent variable. The baseline specification (as all others in the table) includes the full set of controls to allow for the fact that mortality from liver disease and from infectious and parasitic diseases may be associated with the economic cycle and weather. The results show none of the coefficients on the pollutants are statistically significant, apart from a marginally significant coefficient on $\mathrm{O}_{3}$ for mortality from liver disease.

\subsection{Mitigating response to pollution: population mobility}

Our estimates are weighted by the size of the local authority population, giving more importance to local authorities with bigger populations and consequently more reliable mortality measures. ${ }^{23}$ The population size, however, might have an independent impact on mortality other than affecting the precision of the mortality rate. For example, a population could shrink because healthy people leave. Consequently, the proportion of frail people would increase, causing an increase in mortality. If healthy people leave because of upward-trended air pollution, the increase in mortality might wrongly be assigned to the rise in air pollution rather than the fall in population. To test this, row 12 in Table 7 controls for the population size. The coefficients on $\mathrm{PM}_{10}$ and $\mathrm{O}_{3}$ are unaffected. The coefficient on population size is significantly negative. Assuming that changes in the population size are mainly caused by migration, this result supports the idea that healthy people are more mobile, leaving a more frail population behind. These moves, however, do not appear to be a response to pollution levels.

\subsection{Magnitudes}

Our results are statistically significant, but are they economically significant? The withingroup estimates from the penultimate column of Table 4 can be used to examine the effect of a change in $\mathrm{PM}_{10}$ and $\mathrm{O}_{3}$ on mortality. We focus on all-cause mortality.

Assuming no behavioural response (an issue we return to below) a $10 \mu \mathrm{g} / \mathrm{m}^{3}$ increase in $\mathrm{PM}_{10}$, holding all other pollutants fixed, is associated with a $2.7 \%$ increase in the all-cause mortality rate. As the mean all-cause mortality rate is 660 per 100,000 population, this increase equals around 18 more deaths per 100,000 persons. The $10^{\text {th }}$ percentile of the $\mathrm{PM}_{10}$ distribution is $20.9 \mu \mathrm{g} / \mathrm{m}^{3}$, the $90^{\text {th }}$ percentile is $29.0 \mu \mathrm{g} / \mathrm{m}^{3}$, and so a move from the $10^{\text {th }}$ percentile to the $90^{\text {th }}$ percentile of the $\mathrm{PM}_{10}$ distribution would be associated with around 14 more deaths per 100,000 population. A $10 \mu \mathrm{g} / \mathrm{m}^{3}$ increase in $\mathrm{O}_{3}$, holding all other pollutants fixed, is associated with a $0.8 \%$ increase in the all-cause mortality rate. The $10^{\text {th }}$ percentile

\footnotetext{
${ }^{23}$ The results are robust to not weighting. Estimates for the within-group multi-pollutant model with all controls from Table 4 are: $\mathrm{CO}-0.37$ (s.e. $=0.71$ ), $\mathrm{NO}_{2} 0.41$ (s.e. $=0.29$ ), $\mathrm{PM}_{10} 3.02($ s.e. $=0.56)$, $\mathrm{O}_{3} 0.55$ (s.e. $=0.29)$.
} 
of the $\mathrm{O}_{3}$ distribution is $47.1 \mu \mathrm{g} / \mathrm{m}^{3}$, the $90^{\text {th }}$ percentile is $66.4 \mu \mathrm{g} / \mathrm{m}^{3}$, so a move from the $10^{\text {th }}$ to the $90^{\text {th }}$ percentile would be associated with 10 more deaths per 100,000 population.

Alternatively, the difference between the $90^{\text {th }}$ percentile and the $10^{\text {th }}$ percentile of all-cause mortality is 225 deaths per 100,000 population. So, a fall from the $90^{\text {th }}$ to the $10^{\text {th }}$ percentile of $\mathrm{PM}_{10}$ would account for about $6 \%$ of the spread in all-cause mortality, while moving from the $90^{\text {th }}$ to the $10^{\text {th }}$ percentile of the $\mathrm{O}_{3}$ distribution would account for around $4 \%$ of the spread in all-cause mortality.

These effects can be compared to those from the cohort and time series studies. We would expect our estimates to lie between those of the cohort studies, which measure the impact of air pollution over a long period (and cannot control for unobserved heterogeneity across individuals), and the time series estimates, which measure the immediate response to a change in air pollution. The American Cancer Society Cohort Study estimates that a 10 $\mu \mathrm{g} / \mathrm{m}^{3}$ increase in fine particles, $\mathrm{PM}_{2.5}$, would lead to a $6 \%$ increase in all-cause mortality (Pope et al. 2002). The health effects from fine particles are worse than the effects from coarser particles, which the $\mathrm{PM}_{10}$ measure includes but the $\mathrm{PM}_{2.5}$ measure excludes. Thus, we would expect our estimate to be lower. A meta-analysis of the time series studies (Stieb et al. 2002) reports that multi-pollutant models estimate a $0.4 \%$ increase in mortality per 10 $\mu \mathrm{g} / \mathrm{m}^{3}$ increase in $\mathrm{PM}_{10}$. Our estimates indicate a $10 \mu \mathrm{g} / \mathrm{m}^{3}$ increase in $\mathrm{PM}_{10}$ is associated with a $2.7 \%$ increase in mortality. So our estimate is about half the size of that from the cohort study - which has no UK counterpart - and nearly seven times as large as those from times series studies that have been undertaken for the UK. ${ }^{24}$

There is no robust estimate of the effect of $\mathrm{O}_{3}$ from the American Cancer Society Cohort Study. Time series studies estimate a $0.3 \%$ death rate increase per $10 \mu \mathrm{g} / \mathrm{m}^{3}$ increase in $\mathrm{O}_{3}$ in single-pollutant models and a $0.1 \%$ increase in multi-pollutant models (Stieb et al. 2002). In our analysis, a $10 \mu \mathrm{g} / \mathrm{m}^{3}$ increase in $\mathrm{O}_{3}$ is associated with a $0.8 \%$ increase in mortality. Again, our estimate is considerably higher than those from UK studies undertaken to date.

The extent to which we can use our estimates to quantify the effects of a change in pollution depends on whether individuals are likely to take actions to protect themselves from increases in pollution levels. Neidell (2004) finds that people in California respond to information about air pollution (smog alerts) with avoidance behaviour. In England air pollution alerts have to be issued when $\mathrm{NO}_{2}$ levels exceed $400 \mu \mathrm{g} / \mathrm{m}^{3}$ or when $\mathrm{O}_{3}$ levels exceed $360 \mu \mathrm{g} / \mathrm{m}^{3}(240$ $\mu \mathrm{g} / \mathrm{m}^{3}$ since September 2003). Since these thresholds came into force in 2001 no alert has been issued. And while air pollution forecasts are freely available via a variety of sources, ${ }^{25}$ anecdotal evidence shows that use of this information is limited. For example, in 2006 the Sussex Air Quality Partnership piloted a service for respiratory sensitive people that sends air quality forecasts to mobile phones. The study found that the service raised awareness of

\footnotetext{
${ }^{24}$ Our estimate of the impact of $\mathrm{PM}_{10}$ over a year is similar to the impact of a $\mathrm{PM}_{10}$ reduction caused by a 13-month strike at a steel mill in Utah (Pope 1996).

${ }^{25}$ Teletext, the World Wide Web, a Freephone telephone service and weather forecasts in newspapers, on $\mathrm{TV}$ and radio.
} 
pollution episodes and produced health behaviour modifications (Smallbone 2009). However, the same information had been freely available before the service was introduced. Individuals appeared to respond to air quality forecasts only when they received them as personalised messages.

Assuming the extreme position of no behavioural response, our estimates can be used to give a back-of-the-envelope calculation of the benefits of the recent UK policy to reduce the limit value for $\mathrm{PM}_{10}$ to $20.0 \mu \mathrm{g} / \mathrm{m}^{3}$ by 2010. We estimate a $10 \mu \mathrm{g} / \mathrm{m}^{3}$ increase in $\mathrm{PM}_{10}$, holding all other pollutants fixed, is associated with a $2.7 \%$ increase in all-cause mortality. Therefore, reducing $\mathrm{PM}_{10}$ pollution from our sample mean of $24.7 \mu \mathrm{g} / \mathrm{m}^{3}$ to $20.0 \mu \mathrm{g} / \mathrm{m}^{3}$ (a fall of just under 20\%) would be associated with 8.4 fewer deaths per 100,000 population. The population of England is just over 50 million, so this translates into around 4,200 fewer deaths per annum over the whole population of England. Putting a monetary value on these lives saved is less straightforward, because we do not know the life expectancy of those who die prematurely. A value per year of life can be taken from the implicit figure used by the UK body responsible for authorisation of the use of new drugs and therapies in the NHS, which is around $£ 30,000$ (Devlin and Parkin 2004). If we assumed that those who died had another 10 years to live and were healthy, the value of the 42,000 life years gained is around $£ 1,260$ million. ${ }^{26}$ If those who died were less healthy, then our estimate is too high. But as we do not take into account any of the non-mortality costs associated with air pollution, this figure is more likely to be a lower bound. ${ }^{27}$

\section{Conclusions}

We identify the impact of airborne pollutants on mortality from time series variation in annual average pollution levels in English local authorities. Our research is the first to use this design for the UK and one of the few economic studies outside the USA. Our results suggest that currently permitted levels of $\mathrm{PM}_{10}$ and $\mathrm{O}_{3}$ are associated with population mortality, that these pollutants are associated with higher death rates amongst those groups that are likely to be affected by pollution, and that individuals die from those causes that the medical literature indicates are most likely to be associated with pollution. In addition, we find no association

\footnotetext{
${ }^{26}$ This benefit figure is one and a half times the size of the $£ 791$ million expenditure on protection of ambient air and climate by the UK general government sector ( $£ 250$ million) and UK industry (around £541 million) in 2004 (http://www.statistics.gov.uk/downloads/theme_environment/EA_Jun08.pdf and http://www.defra.gov.uk/environment/statistics/envsurvey/expn2004/eerp2004.pdf). It is in a similar ballpark to estimates of the annualised cost of fitting all new cars and lorries with devices that reduce emissions (Department for Environment, Food and Rural Affairs 2007), though it is estimated that this action will decrease $\mathrm{PM}_{10}$ by only 0.8 and not the 4.7 needed to reach the new standard.

${ }^{27}$ If the short run effect of pollution is to kill the frail, our estimates are an upper bound. We repeat this exercise for deaths in the age group 15 to 64 years old, as these individuals are least frail. We estimate that a $10 \mu \mathrm{g} / \mathrm{m}^{3}$ increase in $\mathrm{PM}_{10}$ increases mortality in this age group by $2.3 \%$, so a $4.7 \mu \mathrm{g} / \mathrm{m}^{3}$ drop in $\mathrm{PM}_{10}$ evaluated at the mean mortality rate for this age group, 247 per 100,000 population, would result in 2.7 fewer deaths per 100,000 population. The population of 15 to 64 years old is around 32 million, so the drop in mortality translates into 864 fewer deaths per annum. Assuming these individuals gain only 10 years of life so this estimate will give a lower bound - these 8,640 additional life years are worth $£ 260$ million.
} 
between pollution and causes of death that are not affected by pollutants. This suggests that although we cannot exploit a natural experiment and have to rely on annual time series variation at the local authority level, we do identify a causal relationship.

The relationship that we find between pollution and mortality is for average levels of pollution that are lower than studied in most of the existing research. We find an effect of both $\mathrm{PM}_{10}$ and $\mathrm{O}_{3}$, with the effect being largest and most robust for $\mathrm{PM}_{10}$. Recent economic studies of infants and children in California tend to find lesser effects from $\mathrm{PM}_{10}$ and $\mathrm{O}_{3}$ and more from CO. On the other hand, the adult-focussed epidemiological literature finds shortterm associations between mortality and $\mathrm{CO}, \mathrm{NO}_{2}, \mathrm{PM}_{10}$ and $\mathrm{O}_{3}$, but long-term associations with $\mathrm{PM}_{10}$ only. Our yearly focussed approach has findings that accord with this broader epidemiological literature. Finally, our estimates of the deaths arising from current levels of airborne pollution are considerably higher than those which have been estimated previously using UK data. They are, in fact, closer to those derived from the much less common - and far more expensive - cohort studies. As none of these have been undertaken in the UK, our results suggest that exploitation of the time series variation in annual data at small area level may be used to provide evidence on the longer term impact of airborne pollution. 


\section{Appendix A Sources of $\mathrm{CO}, \mathrm{NO}_{2}, \mathrm{PM}_{10}$ and $\mathrm{O}_{3}$ and their effects on human health}

$\mathrm{CO}$ is a colourless, odourless, poisonous gas, which reduces the body's ability to use oxygen. $\mathrm{CO}$ results from combustion processes under insufficient oxygen supply. Burning fuel containing carbon in idling or slow moving motor vehicles contributes the largest share of CO. A smaller share results from processes involving combustion of organic matter, e.g. power stations and waste incinerators. CO survives in the atmosphere for approximately one month before it oxides to carbon dioxide.

$\mathrm{NO}_{2}$ is a brown, reactive gas with a detectable smell, which is highly toxic in significant concentrations. Relatively high concentrations of $\mathrm{NO}_{2}$ cause inflammation of the airways and can produce broncho-constriction in both asthmatics and non-asthmatics (Committee on the Medical Effects of Air Pollution 1997). $\mathrm{NO}_{2}$ occurs as a primary pollutant (emitted directly from a source) and as a secondary pollutant (formed in the air by reactions of primary pollutants). As a primary pollutant, $\mathrm{NO}_{2}$ is mainly emitted from the tailpipe of diesel vehicles, especially when they move slowly. As a secondary pollutant, $\mathrm{NO}_{2}$ is mainly formed by oxidation of nitric oxide, which is produced by burning fuel at high temperatures. Road transport produces the largest share of $\mathrm{NO}_{2}$. Other important sources of $\mathrm{NO}_{2}$ are power stations and natural gas space heating (Air Quality Expert Group 2004). $\mathrm{NO}_{2}$ converts to nitrates (e.g. nitric acid), which rain or gravity return from the atmosphere to Earth.

Particulate matter has an unspecified chemical composition. Its most important characteristic is the size of the particles. Coarse particles with a diameter of 2.5 to $100 \mu \mathrm{m}$ consist mainly of soil and sea salt elements and are produced by mechanical processes (e.g. suspension of soil in farming and mining, construction, stone abrasion, and sea spray). Coarse particles settle out quickly by gravity. Fine particles with a diameter of 0.1 to $2.5 \mu \mathrm{m}$ consist of primary particles that result from combustion processes and secondary particles that are, for instance, formed by condensation of low volatile compounds and ammonia. Fine particles are too small to settle out by gravity and too large to coagulate into larger particles, therefore they can stay in the atmosphere over days to weeks and travel hundreds to thousands of kilometres before rain returns them from the atmosphere to Earth. Ultra-fine particles with a diameter of 0.01 to $0.1 \mu \mathrm{m}$ have a short residence time in the atmosphere because of their Brownian motion. Particles with a diameter less than $10 \mu \mathrm{m}\left(\mathrm{PM}_{10}\right)$ are inhalable, but 60 to $80 \%$ of particles with a diameter of 5 to $10 \mu \mathrm{m}$ are trapped in the nose and pharynx (Wilson and

Spengler 1996). Smaller particles penetrate the trachea and the primary bronchi. Very small particles penetrate deep into the lungs.

$\mathrm{O}_{3}$ is a bluish, unstable gas with a pungent odour, which is toxic even at low concentrations. It is the "most potent (...) pro-inflammatory pollutant of the common range of air pollutants" (Committee on the Medical Effects of Air Pollution 1997). $\mathrm{O}_{3}$ is a secondary pollutant that is formed by the action of sunlight on volatile organic compounds in presence 
of $\mathrm{NO}_{2}$. It can travel large distances. Nitric oxide, which has high concentrations in urban areas, scavenges $\mathrm{O}_{3}$, resulting in much higher $\mathrm{O}_{3}$ levels in rural areas than in urban areas. As the formation of $\mathrm{O}_{3}$ requires sunlight, $\mathrm{O}_{3}$ levels are highest in summer. 


\section{Appendix B Current air quality standards}

\section{Appendix B.1 Annual}

The annual mean of $\mathrm{NO}_{2}$ must not exceed $40 \mu \mathrm{g} / \mathrm{m}^{3}$ by 31 December 2005 . The annual mean of $\mathrm{PM}_{10}$ must not exceed $40 \mu \mathrm{g} / \mathrm{m}^{3}$ by 31 December 2004 and $20 \mu \mathrm{g} / \mathrm{m}^{3}$ by 31 December 2010 .

\section{Appendix B.2 Daily}

The daily maximum of the running 8 hour mean of CO must not exceed $10 \mathrm{mg} / \mathrm{m}^{3}$ by 31 December 2003. The 24-h mean of $\mathrm{PM}_{10}$ must not exceed $50 \mu \mathrm{g} / \mathrm{m}^{3}$ more than 35 times per year by 31 December 2004. The daily maximum of the running 8-h mean of $\mathrm{O}_{3}$ must not exceed $100 \mu \mathrm{g} / \mathrm{m}^{3}$ more than 10 times per year by 31 December 2005 .

\section{Appendix C Data sources}

Table C-1 provides the data sources for all variables except air pollution.

Air pollution data were downloaded from the web sites of the following networks:

- Automatic Urban and Rural Network (www.airquality.co.uk)

- London Air Quality Network (www.londonair.org.uk)

- Hertfordshire \& Bedfordshire Air Pollution Monitoring Network (www.hertsbedsair.org.uk)

- Kent and Medway Air Quality Monitoring Network (www.kentair.org.uk)

- Sussex Air Quality (www.sussex-air.net)

- South Cambridgeshire District Council (http://scambs-airquality.aeat.co.uk)

- Oxford Airwatch (www.oxford-airwatch.aeat.co.uk)

- Newham Council (http://apps.newham.gov.uk/pollution/)

- Air Quality Monitoring in Slough (www.aeat.co.uk/netcen/aqarchive/slough/site_map.html)

We dropped provisional values, keeping only ratified values. Some data came in volume ratios, which we converted into mass units, using the conversion factors used for reporting data to the European Commission:

- $\mathrm{CO}: 1 \mathrm{ppm}=1.16 \mathrm{mg} / \mathrm{m} 3$

- $\mathrm{NO}_{2}: 1 \mathrm{ppb}=1.91 \mu \mathrm{g} / \mathrm{m}^{3}$

- $\mathrm{O}_{3}: 1 \mathrm{ppb}=2.00 \mu \mathrm{g} / \mathrm{m}^{3}$

We multiply data on $\mathrm{PM}_{10}$ from TEOM analysers by 1.3 and data from BAM analysers by 0.83 to obtain gravimetric equivalent measures. Annual means of pollutant concentrations at station level are based on at least 100 observations. 
Table C-1: Data sources

\begin{tabular}{|c|c|c|}
\hline Variable & Source & Years covered \\
\hline $\begin{array}{l}\text { Mortality rates (per 100,000) } \\
\text { Mortality from all causes } \\
\text { Mortality from all circulatory diseases } \\
\text { Mortality from coronary heart disease } \\
\text { Mortality from acute myocardial infarc- } \\
\text { tion } \\
\text { Mortality from stroke } \\
\text { Mortality from bronchitis, emphysema } \\
\text { and } \\
\text { other chronic obstructive pulmonary dis- } \\
\text { eases } \\
\text { Mortality from chronic liver disease } \\
\text { including cirrhosis } \\
\text { Mortality from infectious and } \\
\text { parasitic diseases }\end{array}$ & $\begin{array}{l}\text { Directly age-standardised } \\
\text { rates from Clinical and } \\
\text { Health Outcomes Knowledge } \\
\text { Baes (www.nchod.nhs.uk), } \\
\text { calculated using data on reg- } \\
\text { istered deaths from Office for } \\
\text { National Statistics (ONS) and } \\
\text { 2001 Census based mid-year } \\
\text { population estimates from } \\
\text { ONS }\end{array}$ & $1998-2005$ \\
\hline $\begin{array}{l}\text { Covariates } \\
\text { Smoking rate, regional level }\end{array}$ & $\begin{array}{l}\text { Clinical and Health Outcomes } \\
\text { Knowledge Base }\end{array}$ & $\begin{array}{l}1998 \\
2000-2005\end{array}$ \\
\hline $\begin{array}{l}\text { Employment rate } \\
\text { Percentage of working age people educated } \\
\text { to degree level or higher }\end{array}$ & $\begin{array}{l}\text { Labour Force Survey } \\
\text { (www.nomisweb.co.uk) }\end{array}$ & 1998-2005 \\
\hline $\begin{array}{l}\text { Annual mean of summer daily } \\
\text { maximum temperature } \\
\text { Annual mean of precipitation }\end{array}$ & $\begin{array}{l}\text { Met Office - } \\
\text { MIDAS Land and } \\
\text { Surface Station Data }\end{array}$ & 1998-2005 \\
\hline
\end{tabular}

Table C-2: Correlation between annual pollutant concentrations

\begin{tabular}{lcccc}
\hline \hline Correlation & $\mathrm{CO}$ & $\mathrm{NO}_{2}$ & $\mathrm{PM}_{10}$ & $\mathrm{O}_{3}$ \\
\hline $\mathrm{CO}$ & 1 & & & \\
$\mathrm{NO}_{2}$ & 0.6 & 1 & & \\
$\mathrm{PM}_{10}$ & 0.4 & 0.6 & 1 & \\
$\mathrm{O}_{3}$ & -0.3 & -0.5 & -0.2 & 1 \\
\hline \hline
\end{tabular}




\section{References}

Air Quality Expert Group: 2004, Nitrogen Dioxide in the United Kingdom, Department for Environment, Food and Rural Affairs, London.

Bell, M. L., Dominici, F. and Samet, J. M.: 2005, A meta-analysis of time-series studies of ozone and mortality with comparison to the National Morbidity, Mortality, and Air Pollution Study, Epidemiology 16, 436-445.

Chay, K., Dobkin, C. and Greenstone, M.: 2003, The Clean Air Act of 1970 and adult mortality, Journal of Risk and Uncertainty 27(3), 279 - 300.

Chay, K. Y. and Greenstone, M.: 2003, The impact of air pollution on infant mortality: Evidence from geographic variation in pollution shocks induced by a recession, The Quarterly Journal of Economics 118(3), 1121-1167.

Clancy, L., Goodman, P., Sinclair, H. and Dockery, D. W.: 2002, Effect of air-pollution control on death rates in dublin, ireland: an intervention study, The Lancet 360, 1210-1214.

Clyde, M.: 2000, Model uncertainty and health effect studies for particulate matter, Environmetrics 11, 745-763.

Committee on the Medical Effects of Air Pollution: 1997, Handbook on air pollution and health, The Stationery Office, London.

Currie, J. and Neidell, M.: 2005, Air pollution and infant health: What can we learn from California's recent experience?., Quarterly Journal of Economics 120(3), 1003 - 1030.

Department for Environment, Food and Rural Affairs: 2007, The air quality strategy for England, Scotland, Wales and Northern Ireland - Volume 1, The Stationery Office, London.

Department of Health: 1998, Smoking kills. A White Paper on tobacco, The Stationery Office, London.

Department of Health: 2000, National service framework for coronary heart disease, Department of Health, London.

Department of Health: 2006, Cardiovascular disease and air pollution - A report by the Committee on the Medical Effects of Air Pollutants, Department of Health, London.

Devlin, N. and Parkin, D.: 2004, Does NICE have a cost-effectiveness threshold and what other factors influence its decisions? a binary choice analysis, Health Economics 13, 437452.

Dockery, D. W. and Pope, C. A.: 1994, Acute respiratory effects of particulate air pollution, Annual Review of Public Health 15, 107-132.

Dockery, D. W., Pope, C. A., Xu, X., Spengler, J. D., Ware, J. H., Fay, M. E., Ferris, B. G. and Speizer, F. E.: 1993, An association between air pollution and mortality in six U. S. cities, The New England Journal of Medicine 329, 1753-1759. 
Georgoulis, L. B., Hänninen, O., Samoli, E., Katsouyanni, K., Künzli, N., Polanska, L., de Bruin, Y. B., Alm, S. and Jantunen, M.: 2002, Personal carbon monoxide exposure in five European cities and its determinants, Atmospheric Environment 36, 963-974.

Gerdtham, U.-G. and Johannesson, M.: 2003, A note on the effect of unemployment on mortality, Journal of Health Economics 22, 505-518.

Griliches, Z. and Hausman, J. A.: 1986, Errors in variables in panel data, Journal of Econometrics 31, 93-118.

Hoek, G., Brunekreef, B., Goldbohm, S., Fischer, P. and van den Brandt, P. A.: 2002, Association between mortality and indicators for traffic-related air pollution in the Netherlands: a cohort study, The Lancet 360, 1203-1209.

Janssen, N. A., de Hartog, J. J., Hoek, G. and Brunekreef, B.: 2000, Personal exposure to fine particulate matter in elderly subjects: relation between personal, indoor and outdoor concentrations, Journal of the Air \& Waste management Association 50, 1133-1143.

Koop, G. and Tole, L.: 2004, Measuring the health effects of air pollution: to what extent can we really say that people are dying from bad air?, Journal of Environmental Economics and Management 47, 30-54.

Kousa, A., Monn, C., Rotko, T., Alm, S., Oglesby, L. and Jantunen, M. J.: 2001, Personal exposures to $\mathrm{NO}_{-} 2$ in the EXPOLIS-study: relation to residential indoor, outdoor and workplace concentrations in basel, helsinki and prague, Atmospheric Environmment 35, 3405-3412.

Krewski, D., Burnett, R. T., Goldberg, M. S., Hoover, K., Siemiatycki, J., Jerret, M., Abrahamowicz, M. and White, W. H.: 2000, Re-analysis of the Harvard Six Cities Study and the American Cancer Society Study of Air Pollution and Mortality, Health Effects Institute, Cambridge, MA.

Nafstad, P., Haheim, L. L., Wisloff, T., Gram, F., Oftedal, B., Holme, I., Hjermann, I. and Leren, P.: 2004, Urban air pollution and mortality in a cohort of Norwegian men, Environmental Medicine 112, 610-615.

Neidell, M.: 2004, Air pollution, health, and socio-economic status: the effect of outdoor air quality on childhood asthma, Journal of Health Economics 23, 1209-1236.

Pope, III, C. A.: 1996, Particulate air pollution and health: a review of the Utah valley experience, Journal of Exposure Analysis and Environmental Epidemiology 6, 23-34.

Pope, III, C. A., Burnett, R. T., Thun, M. J., Calle, E. E., Krewski, D., Ito, K. and Thurston, G. D.: 2002, Lung cancer, cariopulmonary mortality, and long-term exposure to fine particulate air pollution, Journal of the American Medical Association 287, 1132-1141.

Pope, III, C. A., Burnett, R. T., Thurston, G. D., Thun, M. J., Calle, E. E., Krewski, D. and Godleski, J. J.: 2004, Cardiovascular mortality and long-term exposure to particulate 
air pollution. Epidemiological evidence of general pathophysiological pathways of disease, Circulation 109, 71-77.

Pope, III, C. A. and Dockery, D. W.: 2006, Health effects of fine particulate air pollution: lines that connect, Journal of the Air \& Waste Management Association 56, 709-742.

Ruhm, C.: 2000, Are recessions good for your health?, The Quarterly Journal of Economics 115, 617-650.

Smallbone, K.: 2009, Air quality forecasting and its value as a preventive measure for sensitive people - Presentation at Investigation of Air Pollution Standing Conference.

URL: http: //www. iapsc. org. uk/document/1209_K_Smallbone. pdf

Stieb, D. M., Judek, S. and Burnett, R. T.: 2002, Meta-analysis of time-series studies of air pollution and mortality: effects of gases and particles and the influence of cause of death, age, and season, Journal of the Air 63 Waste Management Association 52, 470-484.

Wilkins, E. T.: 1954, Air pollution and the London fog of December 1952, Journal of the Royal Sanitary Institute 74, 1-15.

Wilson, R. and Spengler, J.: 1996, Particle in our air - concentrations and health effects, Harvard School of Public Health, Cambridge, MA. 